\title{
Simulations of Ductile Fracture in an Idealized Ship Grounding Scenario Using Phenomenological Damage and Cohesive Zone Models
}

\section{Citation}

Woelke, Pawel B., Michael D. Shields, Najib N. Abboud, and John W. Hutchinson. 2013.

Simulations of ductile fracture in an idealized ship grounding scenario using phenomenological damage and cohesive zone models. Computational Materials Science 80: 79-95.

\section{Published Version}

doi:10.1016/j.commatsci.2013.04.009

\section{Permanent link}

http://nrs.harvard.edu/urn-3:HUL.InstRepos:11643700

\section{Terms of Use}

This article was downloaded from Harvard University's DASH repository, and is made available under the terms and conditions applicable to Open Access Policy Articles, as set forth at http:// nrs.harvard.edu/urn-3:HUL.InstRepos:dash.current.terms-of-use\#OAP

\section{Share Your Story}

The Harvard community has made this article openly available.

Please share how this access benefits you. Submit a story.

\section{Accessibility}




\title{
SIMULATIONS OF DUCTILE FRACTURE IN AN IDEALIZED SHIP GROUNDING SCENARIO USING PHENOMENOLOGICAL DAMAGE AND COHESIVE ZONE MODELS
}

\author{
Pawel B. Woelke* ${ }^{1}$, Michael D. Shields ${ }^{1}$, Najib N. Abboud ${ }^{1}$ and John W. Hutchinson ${ }^{2}$ \\ ${ }^{1}$ Weidlinger Associates, Inc. \\ 40 Wall Street, New York, NY 10005 USA \\ ${ }^{2}$ School of Engineering and Applied Sciences, \\ Harvard University, Cambridge, MA, 02138, USA
}

\begin{abstract}
Two complementary simulation methodologies for ductile fracture in large sheet metal components are presented and evaluated in this paper. The first approach is based on the phenomenological dilatational plasticity-damage model developed by Woelke and Abboud [68], which accounts for pressure-dependent volumetric damage growth through a scalar damage variable. The damage function represents phenomenologically micromechanical changes the material undergoes during the process of necking. Secondly, the cohesive zone model with an opening mode traction-separation law is employed to simulate the same ductile fracture problems accounting for significant variation of the multiaxial stress state along the crack path. Both methods are examined as to their capabilities to reproduce and predict the outcome of large-scale experimental fracture tests of welded and unwelded ductile plates subjected to large-scale penetration, simulating an idealized ship grounding (Alsos and Amdahl, [1, 2]). The results of the current study indicate that, with appropriate calibration, both approaches can be successfully employed to simulate ductile fracture in structural components under multiaxial stress. The advantages and shortcomings of each approach is discussed from the point of view of post-test numerical investigation as well as its predictive capabilities as an engineering tool.
\end{abstract}

Keywords: Ductile fracture, ship grounding, phenomenological damage model, cohesive zone, large-scale plasticity and fracture, shell mechanics

\section{Introduction}

The subject of ductile fracture of metal sheets and plates has been extensively studied in the literature with contributions from both academic and industrial research institutions. In this work, some recent developments in this field are discussed with a specific focus on simulation and prediction of fracture in large structures, for which use of solid elements is computationally prohibitive. The emphasis is placed on the multiaxial stretching of thin, large plates and shells structures and on the development of the constitutive models and simulation methodologies that allow fracture predictions suitable for such structures.

In most metals, localization of deformation into shear or normal separation bands and subsequent fracture involves the ductile fracture process: void nucleation, growth and coalescence. These microstructural processes can be reliably simulated by means of micromechanical constitutive models explicitly modeling void evolution (e.g. Gurson [25, 26], with modifications [47], Perzyna [51, 53]). Although these models idealize the material as a homogenized continuum, they require that the discretization levels and the scale of the analyzed problem be consistent with the spacing of particles nucleating the voids. As a result, if the full details of the separation process are to be captured, the finite element size must be on the order of $\sim 10-100 \mu$ m (Xue et al. [73]) which has a profound consequence on the scale of the problem that can be realistically analyzed. Modeling fracture and failure of large-scale structures requires bridging the length

*Corresponding author: pawel.woelke@wai.com; Tel.: +1 212367 2983; Fax: +1 2124972483 
scales between the detailed three-dimensional analysis of the material microstructure and realistic structural models of interest to naval, petroleum, aerospace and automotive industries. Various approaches could lead to effective length scale bridging (e.g. hierarchical multiscale modeling). The approach followed in this work is based on formulations embedded in the framework of shell mechanics, which restricts the type of the finite element to a shell element with characteristic length greater than the shell thickness (typical thickness ranging approximately from 0.5 to $2.5 \mathrm{~cm}$ in large structures). In such formulations, the localized area of deformation, whether it be necking or shear localization, is typically smaller than the element, and, thus, localization must be approximately represented by the element. Appropriate shell constitutive models must be formulated and calibrated based on large-scale experimental test data. Herein, we investigate two alternative modeling methodologies, a phenomenological damage model [68] and a cohesive zone model, to address problems of this nature. These methods will be discussed in the following sections of the paper.

We emphasize the importance of the structural scale of the experimental tests. One of the most effective and direct ways of bridging the length scales between the local effects and global modes of failure is to calibrate the model based on experimental tests performed on specimens with the same thickness as those used in the structural components of interest. Both approaches discussed here, i.e. the phenomenological damage and cohesive zone models, will be exercised in this context, with the size of the finite elements determined by feasibility of fracture assessment for large-scale structures (element sizes ranging from $1 \mathrm{~cm}$ to $50 \mathrm{~cm}$ ).

The paper is divided into six sections. After the Introduction, a brief overview of the experimentally observed fracture behavior of metal sheets under biaxial tension is provided. In Section 3, the cohesive zone and phenomenological damage models used in the simulations are discussed. Simulation results for several large penetration problems are given in Section 4. Conclusions are discussed in Section 5 and references provided in Section 6.

\section{Multiaxial Stretching of Thin Metallic Plates}

While plastic behavior of uniformly deforming metals is not significantly influenced by pressure (mean stress), ductile fracture depends strongly on stress triaxiality (mean stress divided by effective Mises stress). In particular, the onset of necking leads to changes in stress triaxiality within the neck due to changes in geometry and non-uniform deformation. Necking promotes higher stress triaxiality and a corresponding reduction in ductility. Pressure-dependent failure in metals has been observed experimentally [34, 44, 45, 60] and recognized by early constitutive formulations based on micromechanical observations of void evolution (McClintock [44], Rice \& Tracey [55], Gurson [25], Fleck \& Hutchinson [20], Hutchinson \& Tvergaard [31], Seweryn \& Mroz [59], Tvergaard \& Hutchinson [63], Johnson \& Cook [34]). More recent experimental data Bao and Wierzbicki [7], as well as Barsoum and Faleskog [8, 11] and corresponding constitutive models [6, 47] have also emphasized the importance of shear stresses versus axisymmetric stress states and the corresponding influence on ductility. In the current work which focusses on plane stress states, we are interested in fracture over a range which spans uniaxial tension (triaxiality of $1 / 3$ ), plane strain tension (triaxiality of $1 / \sqrt{3}$ ) and equi-biaxial tension (triaxiality of 2/3). In this context, the sheet forming limits originally developed by Marciniak and Kuczynski [42] offer great insight into material instability under multiaxial stretching with varying levels of stress triaxiality (or biaxiality). Marciniak and Kuczynski determined the onset of necking instability (as opposed to fracture) of drawn plates to establish 
the strain level for sheet forming which should not be exceeded for localized thinning and fracture to be avoided. This work resulted in development of forming limit diagrams (FLDs) for sheets. Although, the forming limits are based on the analysis of instability (i.e. onset of necking as opposed to fracture) of thin sheets in plane stress, they provide useful information about macroscopic fracture behavior of metals under biaxial stress states because, once the throughthickness necking instability sets in, essentially no further strains occur outside the localized necking region. The forming limit strains provide an excellent measure for engineering purposes of the maximum overall strains the sheet can sustain prior to fracture. A sample FLD, based on experimental tests specifically designed to target ranges of biaxial stress of interest, is shown is Figure 1 [35].

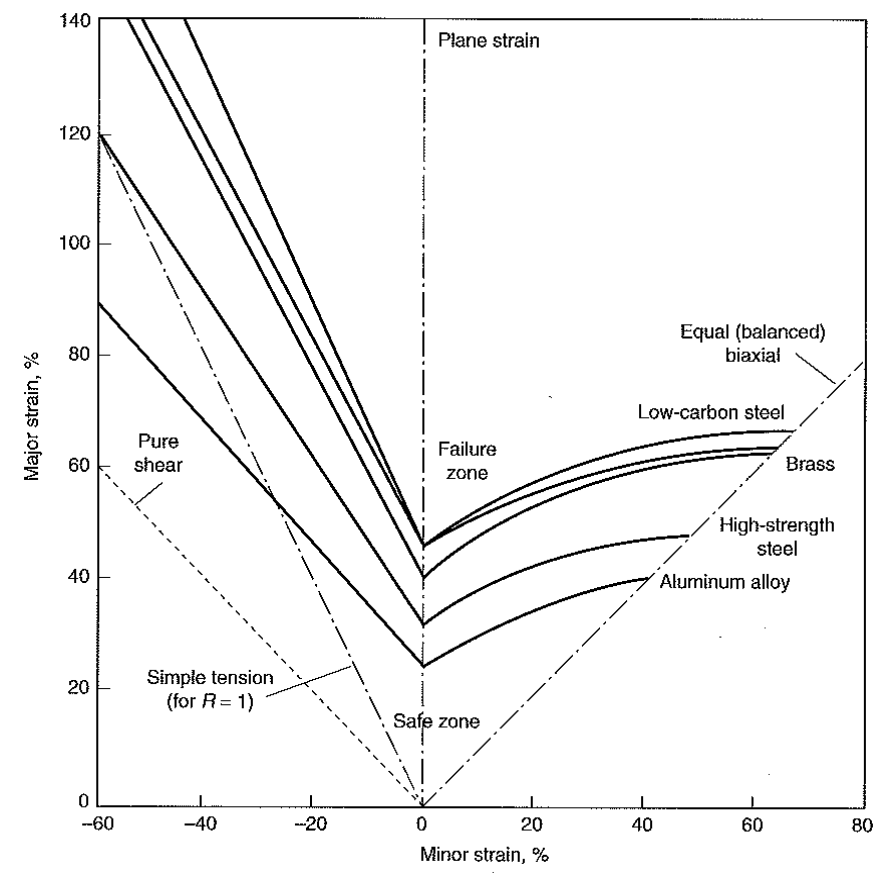

Figure 1 - Forming-limit diagram for various sheet metals [35]

We note that the results plotted in the forming-limit diagram given in Figure 1 lead to similar conclusions as those drawn by Bao and Wierzbicki regarding the influence of the stress triaxiality and associated ductility reduction. The minimum major strain at onset of necking in metal sheets occurs under plane strain conditions, with strains at necking being $~ 15 \%$ lower than those for necking in equibiaxial tension. This suggests that fracture of sheets in plane strain should also occur at lower strain levels than in equibiaxial tension, which is consistent with the fracture data by Beese et al. [12] and Li and Wierzbicki [42].

Korkolis and Kyriakides [37, 38] and Korkolis et al. [39] recently conducted a series of experiments on aluminum tubes subjected to internal inflation causing burst. The tests were carefully designed to investigate the localization and fracture under different radial stresses (which can be related to stress biaxiality) and strain paths. While the geometry of the specimens, as well as the loading conditions are different from those in the case of sheet drawing, both tests effectively measure behavior of aluminum sheets under multiaxial tension. The experimental results obtained by Korkolis et al. [39] are shown in Figure 2. 

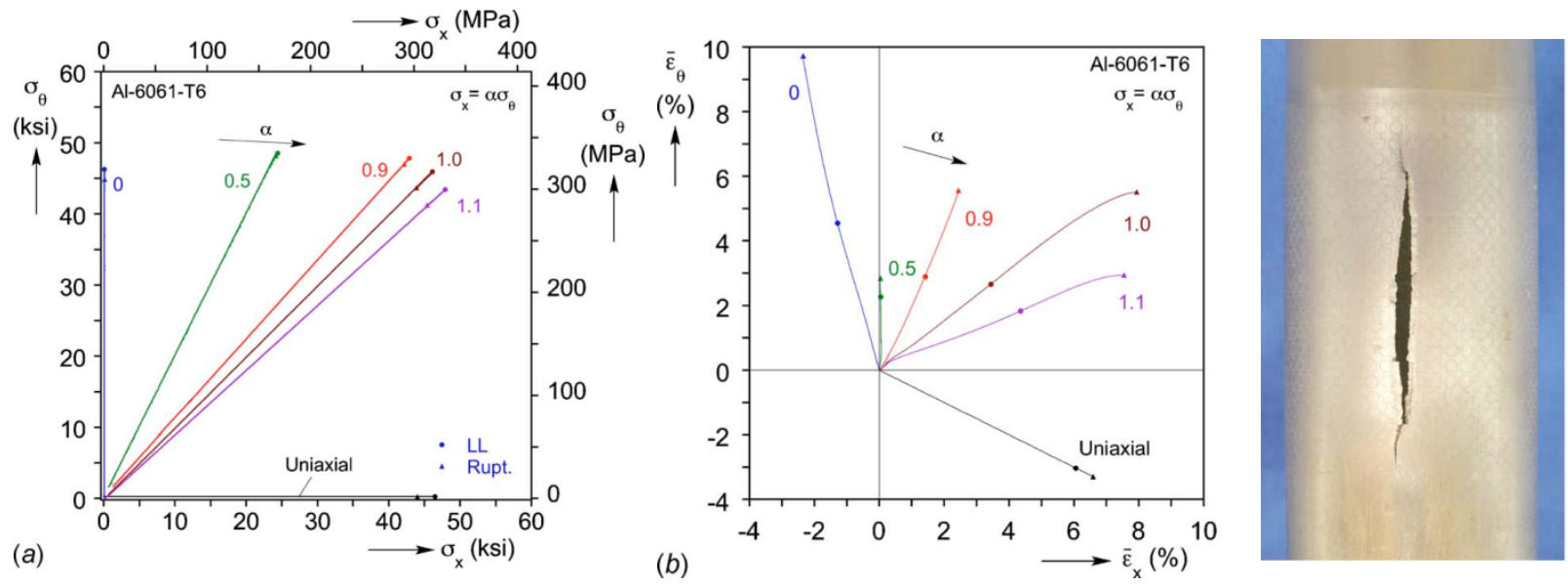

Figure 2 - Experimental measurements of burst in aluminum tubes: (a) prescribed radial stress paths; (b) induced engineering strain paths and failed specimen under biaxiality of $\boldsymbol{\alpha}=\mathbf{0 . 9}$ [39]

Investigation of the stress-strain behavior in the circumferential direction indicates that localization and failure occur at the lowest strain levels when the biaxiality ratio $\alpha=0.5$ (corresponding to a plane strain condition with straining purely in the circumferential direction). Under equibiaxial stress $(\alpha=1.0)$, localization and failure occur at higher strain than the plane strain case, but significantly lower than the uniaxial case $(\alpha=0)$. The data clearly shows the dependence of the strain at onset of necking and fracture on the biaxiality ratio (related to triaxiality) as well as the strain paths. Comparison of the strain paths under biaxiality $\alpha=0$ for axial and circumferential directions indicates presence of anisotropy. The observed general trends of the instability-biaxiality dependence are consistent with the forming limit diagram shown in Figure 1.

Similar conclusions could be drawn from other recent experimental tests such as those conducted by Bao \& Wierzbicki [7] and Barsoum \& Faleskog [10, 11]. The focus of the current study is on cases where localization and ductile fracture occur in multiaxial tension, which motivated the choice of the test data used to calibrate the constitutive model. The experiments discussed above illustrate the complexities associated with ductile fracture and show that any reliable fracture modeling methodology must be consistent with measured behavior of materials and structures subjected to multiaxial stressing. The trends reviewed above cannot be extracted from uniaxial tension material data alone, as is assumed in some engineering analyses.

\section{Modeling Methodologies}

\subsection{Cohesive Zone Model}

The cohesive zone approach is a direct application of the strip-yield model first developed by Dugdale [17] and Barrenblat [8]. In this model, the material behavior in the extended crack tip (or cohesive zone) is described by an internal traction-separation relationship, commonly referred to as the cohesive law. The extended crack tip with cohesive tractions resisting the crack opening is illustrated in Figure 3 (modified from [17]) where $2 L$ is the crack length, and $s$ is the length of the extended crack tip (i.e. size of fracture process zone). 


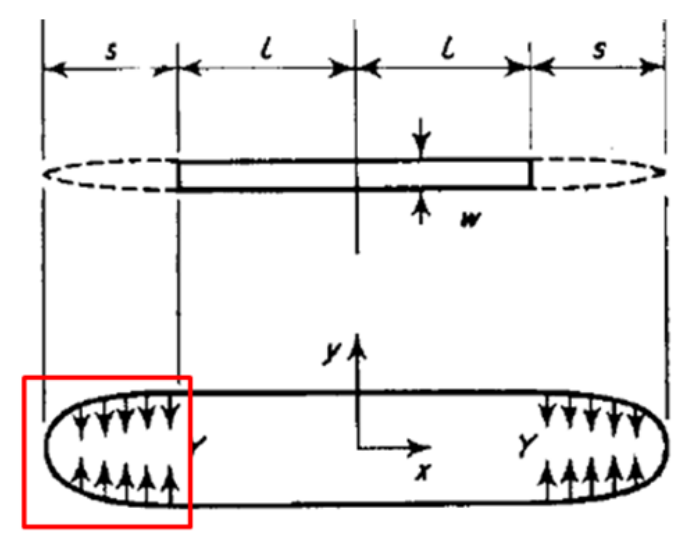

Figure 3 - Strip-yield model with internal tractions in the cohesive zone [17]

The traction-separation relationship (or cohesive law) can be regarded as a macro-scale 'homogenized' representation of the micromechanical behavior of the material at the crack tip, which provides a useful and effective method of analysis of crack initiation and propagation. Both tangential and normal strength can be used to characterize the cohesive law, as well as work of separation (cohesive energy) per unit area, which introduces the characteristic length [73]. This characteristic length helps to regularize the problem and ensure objectivity of the solution. An example of the cohesive law function for symmetric separation is shown in Figure 4 [51] where $t$ denotes the cohesive traction, $\delta$ denotes the separation, $\mathrm{G}_{c}$ denotes the cohesive energy, $\sigma_{c}$ denotes the maximum cohesive traction, and $\delta_{c}$ denotes the separation corresponding to $\sigma_{c}$.

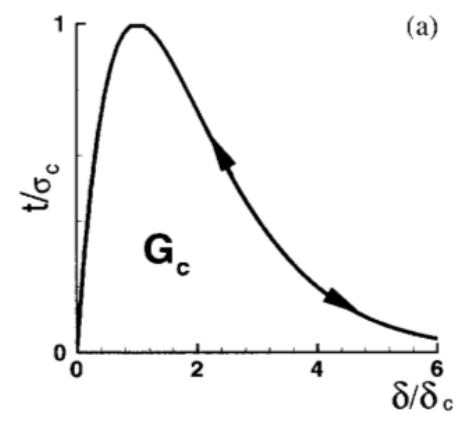

Figure 4 - Smith-Ferrante type non-linear cohesive law [51]

The key parameters that characterize the cohesive law (per separation mode) are the peak traction (or cohesive strength), and the cohesive energy $G_{c}$, corresponding to the energy dissipated in the fracture process zone. In the current work we consider the normal separation mode, i.e. mode I. The cohesive energy is defined as:

$$
\mathrm{G}_{c}=\int_{0}^{\delta_{c r}} t d \delta
$$

where $\delta_{c r}$ is the cohesive separation when the separation traction drops to zero. The shape and the functional form of the cohesive traction-separation relationship is generally of smaller significance than peak traction and the energy.

Cohesive zone models provide an effective method for analysis of crack propagation in the context of the finite element method. Implementation involves introducing the cohesive elements 
at interfaces between standard finite elements allowing for inter-element separation, which simulates the fracture process. There is a variety of different types of cohesive elements ranging from quadrilateral elements, which are typically introduced as a surface on the boundary between 3D elements, or line elements, which are used on the interface of quads. Cohesive zone elements do not represent any specific material, but rather describe the cohesive forces (or tractions), which resist material separation in the cohesive zone. As such, the cohesive elements represent behavior of the material that cannot be accurately captured by the standard finite elements, unless advanced softening constitutive models are employed (e.g. phenomenological damage model). In the context of deformation of sheets and plates, the standard finite elements model the material behavior until the onset of necking, and the cohesive zone simulates the deformation past that point until complete crack opening. Therefore, the traction-separation relationships that define the cohesive zone represent only the material behavior from the onset of localization until failure. We also stress that, in the current work, this methodology is meant to provide a 'global', large-scale approximation of the complicated localization and fracture processes.

It is worth noting that cohesive zone models are particularly well suited for modeling welded aluminum structures in which the weld causes a significant strength reduction in the heat affected zone (HAZ). In such cases, a 30 to $50 \%$ strength reduction may occur in the HAZ compared to the parent material. Furthermore, aluminum welds may have significantly reduced ductility, which makes the mode of failure and its location predictable. Cohesive zone models are ideally suited to modeling these types of fractures because the location of the cohesive zone can be assumed a priori. In general, cohesive elements may be used at all nodal points and degrees of freedom [73]. However, this is not practical for large-scale analysis and the cohesive elements are placed only along potential fracture paths. Fracture simulation of welded aluminum components has been discussed by the authors in a separate paper [60].

One of the most important considerations in finite element modeling of fracture is objectivity of the solution. The objective solution should not show significant sensitivity to the element size. This is accomplished by use of a cohesive zone model because the regions of the plate that are hardest to resolve, such as a neck in a developing crack and the shear bands that form within the neck, are subsumed by the cohesive zone representation. The cohesive zone representation must be calibrated using coupon-level test data or, possibly, simulations for a specific plate thickness. It is anticipated that the length of the cohesive zone is large compared to the plate thickness. It is essential that the finite elements bordering the cohesive zone must be fine enough to resolve the distribution of cohesive separation within the zone. In addition, based on the experimental data reviewed in Section 2, a reliable fracture simulation methodology must account for the effect of stress triaxiality (or biaxiality in the case of biaxial tension). A cohesive zone model with explicit dependence on triaxiality (as well as strain rate) is currently under investigation by the authors, based on the work of Anvari et al. [1]. In the current work, location-specific cohesive laws are used which depend on the location along the crack path, or more exactly, to the varying levels of stress biaxiality along the crack path. The consequences of this approach, along with the model calibration procedure, are discussed in Section 4.

\subsection{Phenomenological Damage Model}

The second approach employed here for large-scale ductile fracture simulation uses an advanced dilatational plasticity model with a scalar damage variable governing softening behavior. This damage variable is purely phenomenological and does not have any direct physical interpretation, (i.e. it cannot be measured experimentally). It is intended to provide a global 
representation of the micromechanical changes the material undergoes during the process of localization and fracture. The constitutive equations governing the model are formulated in the framework of shell mechanics, allowing for fracture simulations of large structures for which use of three-dimensional elements is prohibitive. The model can be used with any standard shell element formulation with multiple integration points through the thickness. In the thick-shell formulation, the zero-transverse normal stress condition must be explicitly enforced, and for thin shell analyses, a full plane stress condition is required. A complete description of the phenomenological damage model, along with the derivation of the governing equations (both in the stress and stress-resultant space) are provided by Woelke and Abboud [68], Woelke et al. [69] and Voyiadjis and Woelke [66-67]. Only the most important characteristics of the model are discussed here, emphasizing the key assumptions and capabilities of the model.

The plastic potential function with a scalar damage variable $\xi$ can be written as follows:

$$
f=\sqrt{\frac{3}{2} S_{i j} S_{i j}+n \xi \sigma_{i i}^{2}}
$$

where $n$ is a model parameter controlling the pressure- and damage-dependent reduction of the size of the yield surface, and $S_{i j}$ is the deviatoric stress tensor given by:

$$
S_{i j}=\sigma_{i j}-\frac{1}{3} \sigma_{k k} \delta_{i j}
$$

where $\sigma_{i j}$ is the stress tensor and $\delta_{i j}$ is the Kronecker delta.

We note that the plastic potential given by equation (2) has a similar form to a standard J2 plasticity (or Huber-Mises-Hencky), except that it includes a pressure-dependent term that is also a function of the damage variable. The model is therefore of a dilatational plasticity type, with a smooth, hardening-softening yield surface which reduces to J2 plasticity if damage is zero. The potential function (2) is taken to be homogeneous of degree two in the stress. In the problems under consideration in this paper, the mean stress term in (2) is intended to capture the mean stress influence in the stress triaxiality range from roughly $1 / 3$ to $2 / 3$.

The evolution of the damage variable is dependent on the expansive, volumetric plastic strain as:

$$
\dot{\xi}=K \dot{\varepsilon}_{k k}^{p}
$$

where $K$ is a model calibration function, given by:

$$
K=k_{1} \exp \left(k_{2} \frac{\varepsilon_{e q}^{p}}{N}\right) ; \quad \varepsilon_{e q}^{p}=\sqrt{\frac{2}{3} \varepsilon_{i j} \varepsilon_{i j}}
$$

$k_{1}$ and $k_{2}$ are calibration parameters, $N$ power law material hardening exponent, and $\varepsilon_{e q}^{p}$ is the equivalent plastic strain. The damage evolution given by equation (5) requires an assumption of the initial damage value $\xi_{0}$, which exists in the material before the loading is applied.

The above constitutive equations can be used in a stress or stress resultant space, in conjunction with a layered or non-layered shell element. Both options have been implemented into the explicit dynamic finite element codes EPSA [4-5, 70, 71, 72] and Flex [65], which feature a variety of different shell elements. The results discussed in this paper, have been obtained with a stress-resultant formulation, which has been described in detail by Woelke [68-69] as well as Voyiadjis and Woelke [66-67]. The limiting yield surface in the stress resultant space is the same as the one originally formulated by Iliushin [33]: 


$$
F_{L}=I_{N}+\frac{M_{0}^{2}}{M_{L}^{2}} I_{M}+\frac{1}{\sqrt{3}} \frac{M_{0}}{M_{L}} I_{N M}-\frac{Y\left(W_{p}\right)}{\sigma_{y}^{2}} ; M_{L}=\frac{\sigma_{y} h^{2}}{4}
$$

where the stress intensities have been modified to include the effect of damage [66-69] and transverse shear forces as follows:

$$
\begin{gathered}
I_{N}=\frac{1}{N_{0}^{2}}\left[\left(1+\frac{1}{2} n \xi\right)\left(N_{11}^{2}+N_{22}^{2}\right)-(1-n \xi) N_{11} N_{22}+3\left(N_{12}^{2}+N_{13}^{2}+N_{23}^{2}\right)\right] \\
I_{M}=\frac{1}{M_{0}^{2}}\left[\left(1+\frac{1}{2} n \xi\right)\left(M_{11}^{2}+M_{22}^{2}\right)-(1-n \xi) M_{11} M_{22}+3 M_{12}^{2}\right] \\
I_{N M}=\frac{1}{N_{0} M_{0}}\left[\left(1+\frac{1}{2} n \xi\right)\left(N_{11} M_{11}+N_{22} M_{22}\right)-\frac{1}{2}(1-n \xi)\left(N_{11} M_{22}-N_{22} M_{11}\right)\right. \\
\left.+3 N_{12} M_{12}\right] \\
N_{0}=\sigma_{y} h ; M_{0}=\frac{\sigma_{y} h^{2}}{6}
\end{gathered}
$$

The above equations give the initial and limiting yield surfaces, which correspond to first yield and full plastification of the cross section. The intermediate surfaces that allow capturing the progressive plastification of the cross section when bending occurs can be obtained by using the plastic curvature parameter proposed by Crisfield [16], or a variable yield surface proposed by Atkatsh et al. [4-5]. The latter was used in the current investigations.

In light of the discussion in the introduction, we consider elements that are similar in size to (generally larger than) the typical gauge length over which the strain is measured in a uniaxial tensile test. It is important to note that the strains are considered homogenized over the gauge length. Gauge length reduction leads to higher values of measured critical failure strain, which is a consequence of high strain gradients between the center of the neck and outside of it. Consequently, critical failure strain measurements taken within the neck (based on grain width reduction for example) can reach levels close to $100 \%$ or higher, depending on the material [29], while the same measurement based on the typical gauge length of $5 \mathrm{~cm}$ will give values in the range of $10-30 \%$ (for ductile metals). One of the key objectives of the current methodology is to represent necking and fracture with a single element of length similar to (or greater than) the typical gauge length $(\sim 5 \mathrm{~cm}$ for a plate of thickness of $\sim 0.5 \mathrm{~cm})$. Plate necking is associated with a localized through-thickness reduction of the plate, which leads to nominal stress reduction and significant energy dissipation between the onset of necking and onset of shear band localization within the neck [50]. Capturing the material softening as well as the geometric effect of thinning with a single shell element (on the level of engineering stress-strain behavior) requires modifying the material softening law, such that it combines the geometric and material effects. This is accomplished here by representing the increased rate of damage growth caused by localization through the calibration function given in equation (5).

One coupon-level plate stretching test that was used to calibrate (5) is a thin strip of plate in uniaxial tension. The thin strip test displays necking at two levels. The Considere condition for uniaxial tension corresponds to the onset of diffuse when the strain is equal to the hardening exponent $(N)$. This is not a through-thickness neck, but rather a broad neck whose width is comparable to the width of the strip. The diffuse neck is not relevant to the calibration process. As the specimen is further stretched a through-thickness neck with width comparable to the plate 
thickness sets in, typically at strains that can be as much as $50 \%$ or more greater than $(N)$, as is evident in Figure 1. It is this through-thickness neck and the subsequent deformation and failure processes which are relevant to the calibration for uniaxial tension. The calibration functions given by (4) and (5), capture a relatively slow rate of damage growth prior to the onset of necking and an strong increase in the rate of damage growth after the onset of necking. The parameters $k_{1}$ and $k_{2}$ allow for calibration of the model to accurately represent the observed tensile behavior of most ductile metals.

An example of the damage model material fit calibrated against uniaxial tensile test data collected by Alsos et al. [1-2] for mild steel (S235JR EN10025) is given in Figure 5. The model parameters $n, k_{1}, k_{2}$ and $N$ were calibrated to accurately represent the observed behavior using a single $1.2 \mathrm{~cm}$ shell element.

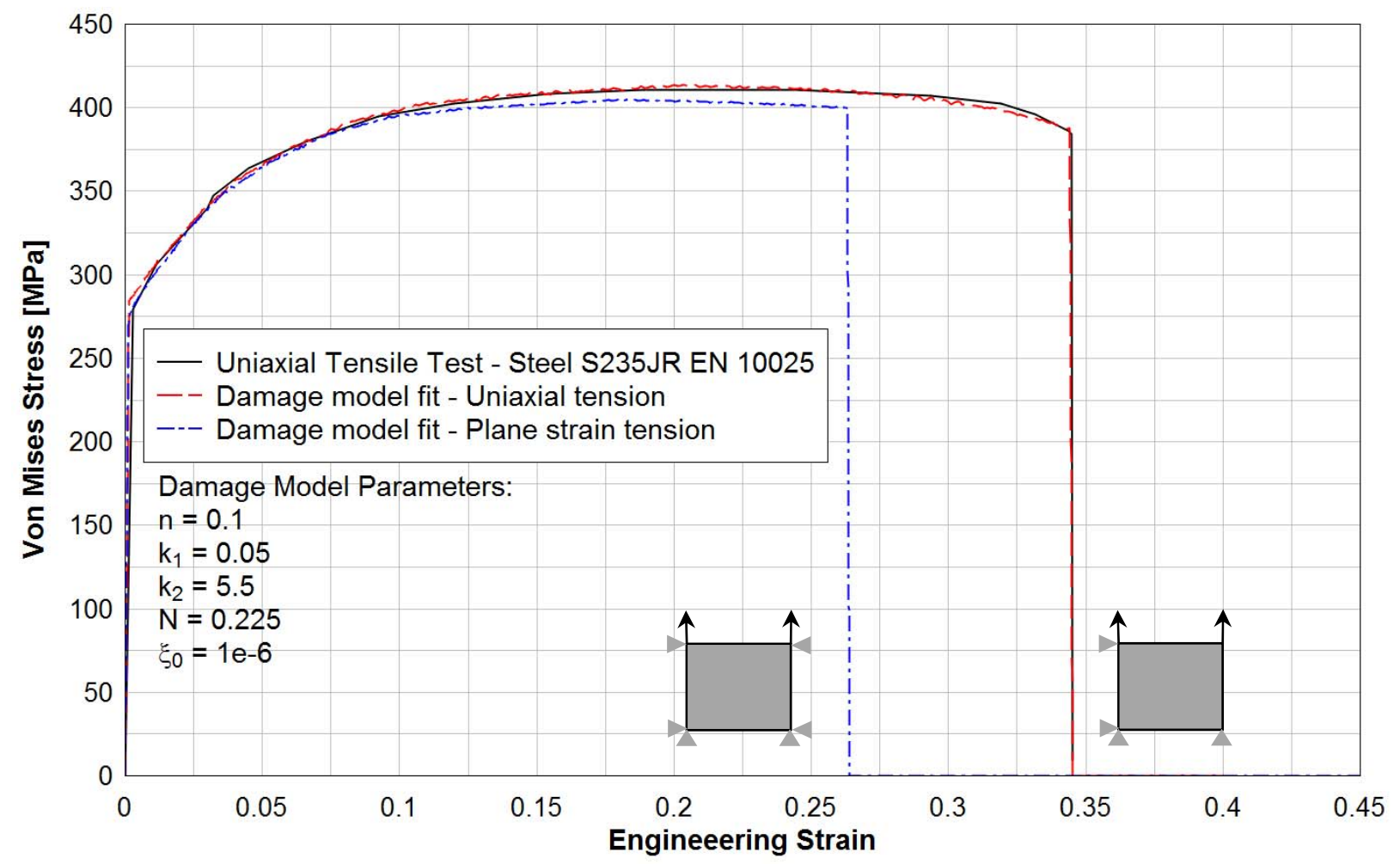

Figure 5 - Mild steel S235JR EN10025 uniaxial tensile test data [1-2] and corresponding damage model calibration based on the single element analyses; uniaxial tension and plane strain tension

The gauge length used during the uniaxial tensile test was not known, so a length of $5 \mathrm{~cm}$ was assumed for initial calibration of the uniaxial tensile response. As shown in Figure 5, the damage model representation of uniaxial tension matches very closely the measured response. The model prediction of behavior in plane strain tension, however, is of equal importance. Based on the experimental test results discussed in Section 2, the onset of necking (and correspondingly the failure strain) is significantly lower in plane strain than in uniaxial tension. The optimal way to calibrate the present phenomenological damage model is to use some combination of uniaxial, plane strain and equibiaxial tensile tests. In absence of the biaxial tensile data, we aimed to recognize the general trend suggested by the forming limit diagram for steel, indicating that the 
onset of necking in plane strain can occur at approximately $30-50 \%$ lower strain than in the case of uniaxial tension. This is well represented in the current model, as shown in Figure 5. The material model calibrated as described above (based on the uniaxial tensile test and forming limit data) is used as a basis for analysis of the plate penetration problems discussed in the following section.

As previously discussed in the context of the cohesive zone model, objectivity of the solution is of paramount importance for finite element modeling of fracture. To accomplish this objectivity, the damage model requires a length scale regularization procedure that accounts for the fact that the failure strain measured in the uniaxial tensile test is gauge-length-specific. Regularization of the fracture energy by the ratio of the gauge length to the characteristic element size significantly reduces mesh dependency of the solution. The work of Woelke and Abboud [68] describes the details of this regularization procedure.

\section{Simulation of Large Plate Penetration}

The details of the experiments and corresponding finite element analyses are discussed in this section. All simulations were conducted using quadrilateral, constant strain shell elements with Mindlin-Reissner thick shell kinematics and stress-resultant shell constitutive equations (Section 3.2). The details of the kinematics of the element, shell equations, solution of the equations of motion and time integration scheme are available in references [4, 5, 68, 70, 71, 72].

\subsection{Test Specimens and Experimental Setup}

The focus of the current work is on the large-scale plate penetration with application to ship grounding. The ship grounding experiments were conducted by the U.S. Naval Surface Warfare Center, as reported by Rodd et al. [56, 57]. These types of tests are extremely valuable from the point of view of understanding the effects of ship grounding and collision, which involve extensive tearing and structural failures. Controlled plate penetration experiments have recently been conducted by Alsos et al. [1-2]. These tests are, to a certain extent, similar to ship grounding investigations in that they involve large component level specimens subjected to penetration by a large conical penetrator with a spherical 'nose' that simulates a rock. While full scale grounding experiments offer great insight into general ship behavior, the penetration tests provide a more detailed look into the mechanics of multiaxial deformation and ductile fracture of metal plates, since they trace discrete fracture initiation and propagation.

We investigate two configurations of large steel plates subjected to slow penetration by a rigid conical indenter (Figure 6): (1) an unstiffened monolithic plate with no center-line weld and (2) a stiffened plate with a single flat bar stiffener welded to the underside of the plate, directly under the indenter. 
(a)
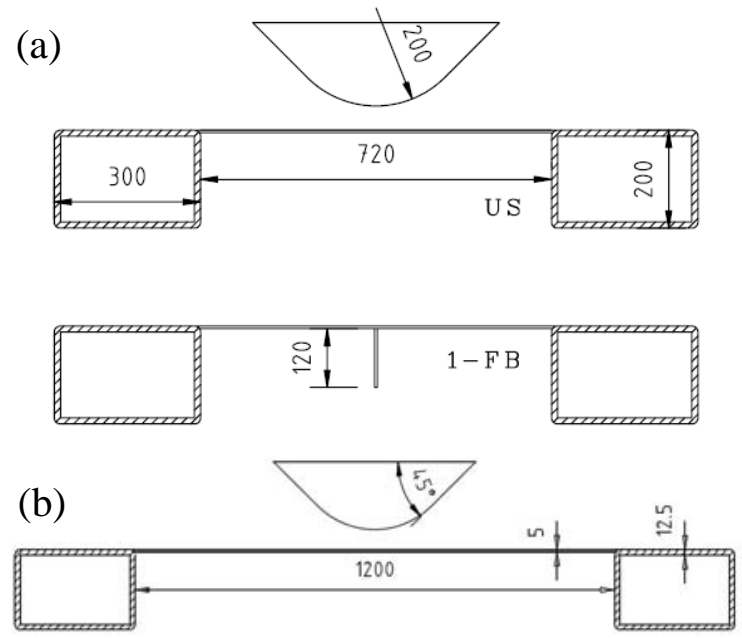

Figure 6 - Penetration tests configurations showing (a) transverse and (b) longitudinal crosssections; panel labels correspond to component type and stiffener configuration (US-unstiffened, 1-FB - single flat bar stiffener) [1-2].
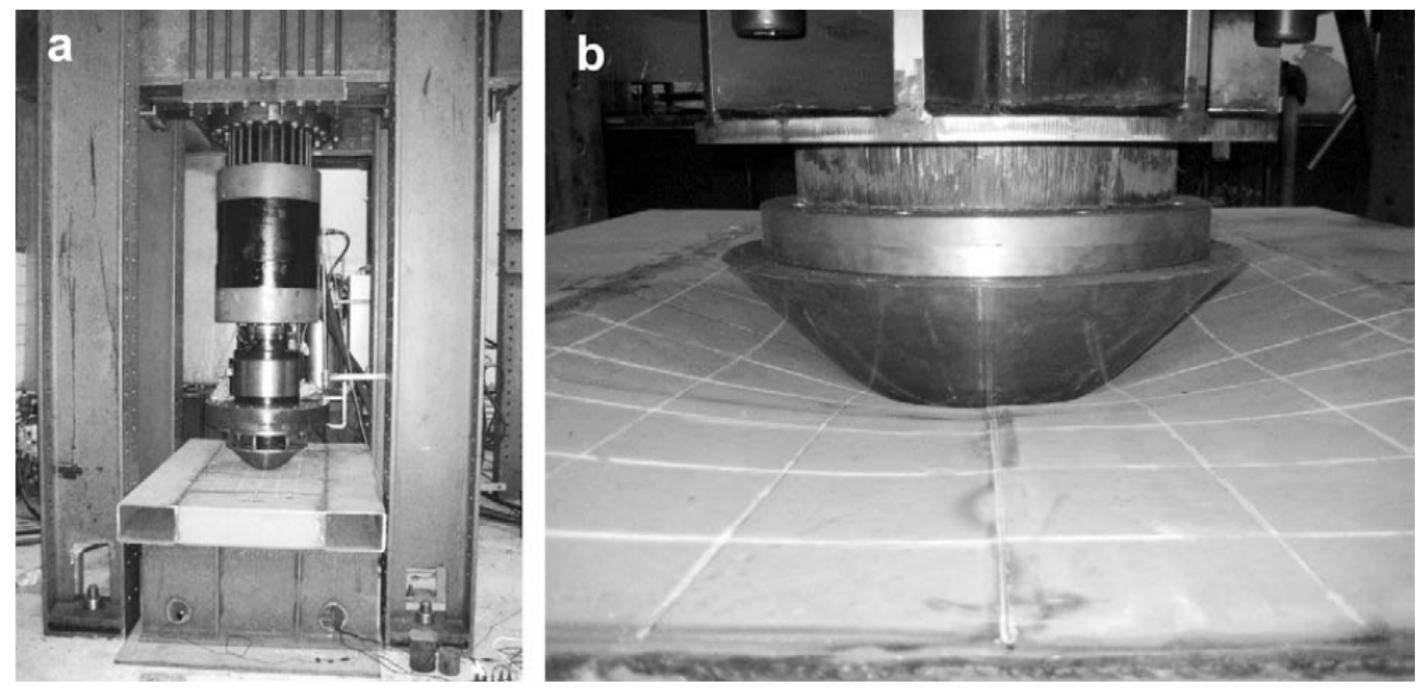

Figure 7 - Penetration test setup: (a) test rig with a hydraulic jack, (b) plate deforming under the indenter [1-2]

The plates were welded to a stiff box frame constructed from steel tube sections following a typical shipyard procedure, which makes the test data valuable for ship applications as well as other marine structures. The hydraulic jack shown in Figure 7 forced the indenter into the plate at a quasi-static rate of $100 \mathrm{~mm} / \mathrm{min}$, until fracture. Further details of the experimental set-up are provided by Alsos and Amdahl [1].

The measured global force vs. indenter displacement for the two plates of interest (1-FB and US) are shown in Figure 8 [1-2]. Due to limited stroke of the hydraulic jack used in the tests, the plate had to be unloaded and reset before loading to failure, as visible in Figure 8. 


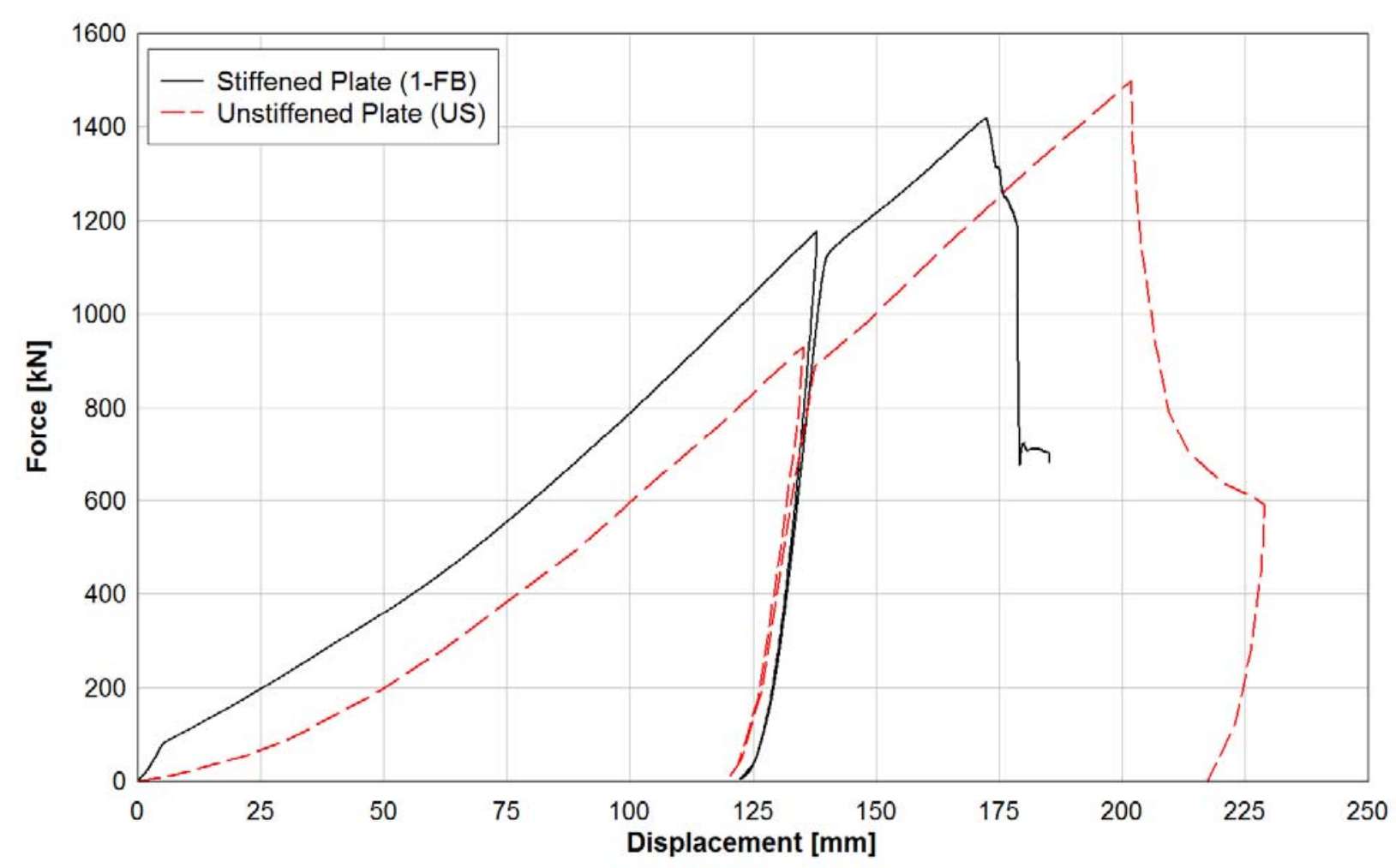

Figure 8 - Measured force vs. indenter displacement for the stiffened plate (1-FB) and the unstiffened plate (US) [1]

\subsection{Flat Bar Stiffened Plate}

First, we consider penetration of the stiffened plate. Both the stiffener and the plate were manufactured from S235JR EN10025 mild steel, albeit from different batches. Uniaxial tensile tests of the plate and stiffener material were conducted to characterize the material response. Engineering stress-strain plots obtained from these tests are shown in Figure 9. 


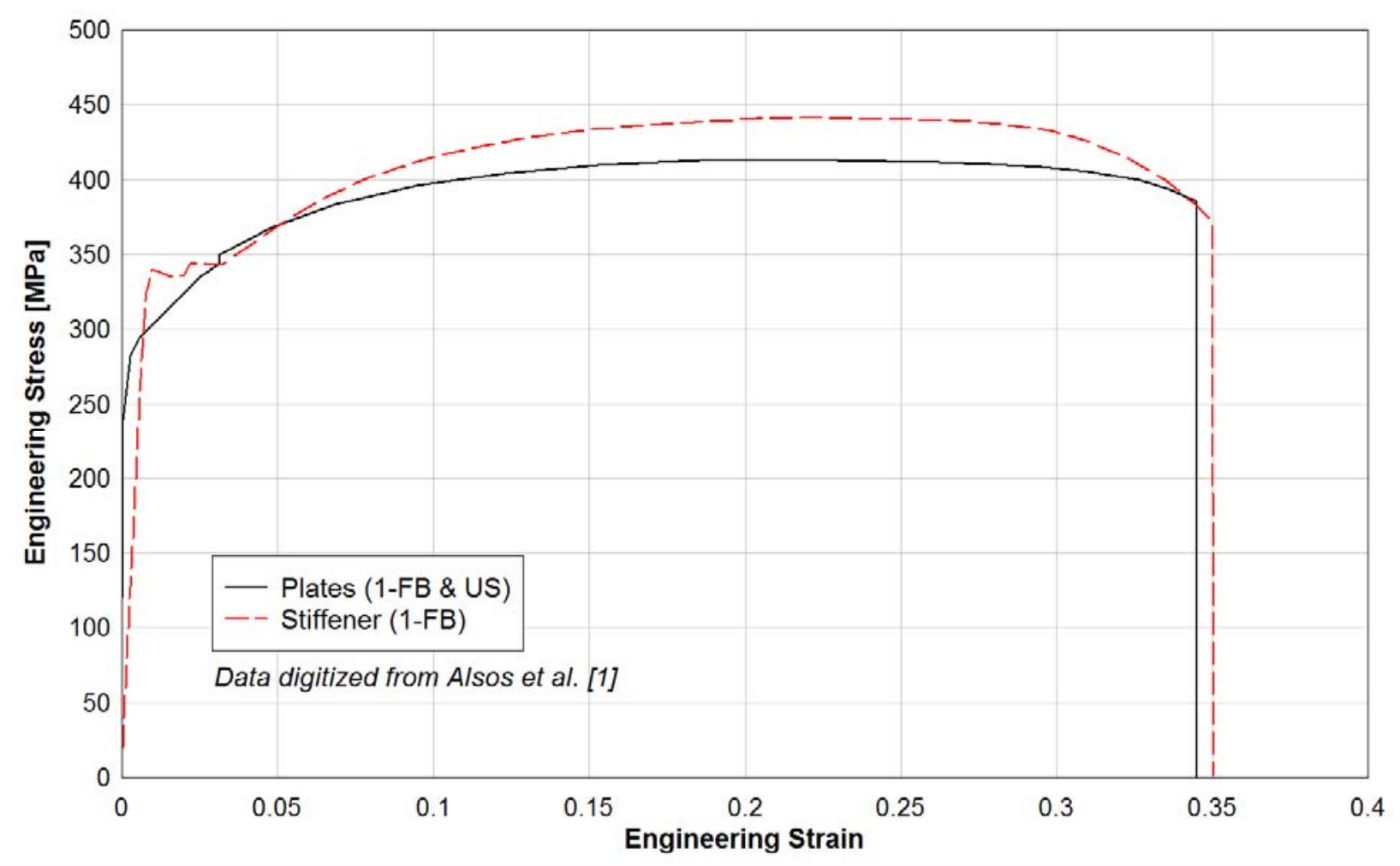

Figure 9 - Engineering stress-strain plots of the plate and stiffener materials [1]

The observed difference in the uniaxial stress-strain response of the samples from the plate and the stiffener was likely due to the fact that different steel batches were used to manufacture the plate and the stiffener, as discussed by Alsos and Amdahl [1].

The progress of the plate deformation is shown in Figure 10. At first, the deformation is dominated by biaxial stretching (with various levels of biaxiality) in the plate, combined with stiffener bending. At a certain point, the stiffener buckles (or trips) but does not fracture. Fracture then initiates in the plate at the weld toe near the location where the indenter loses contact with the plate, as discussed by Alsos et al. [2].
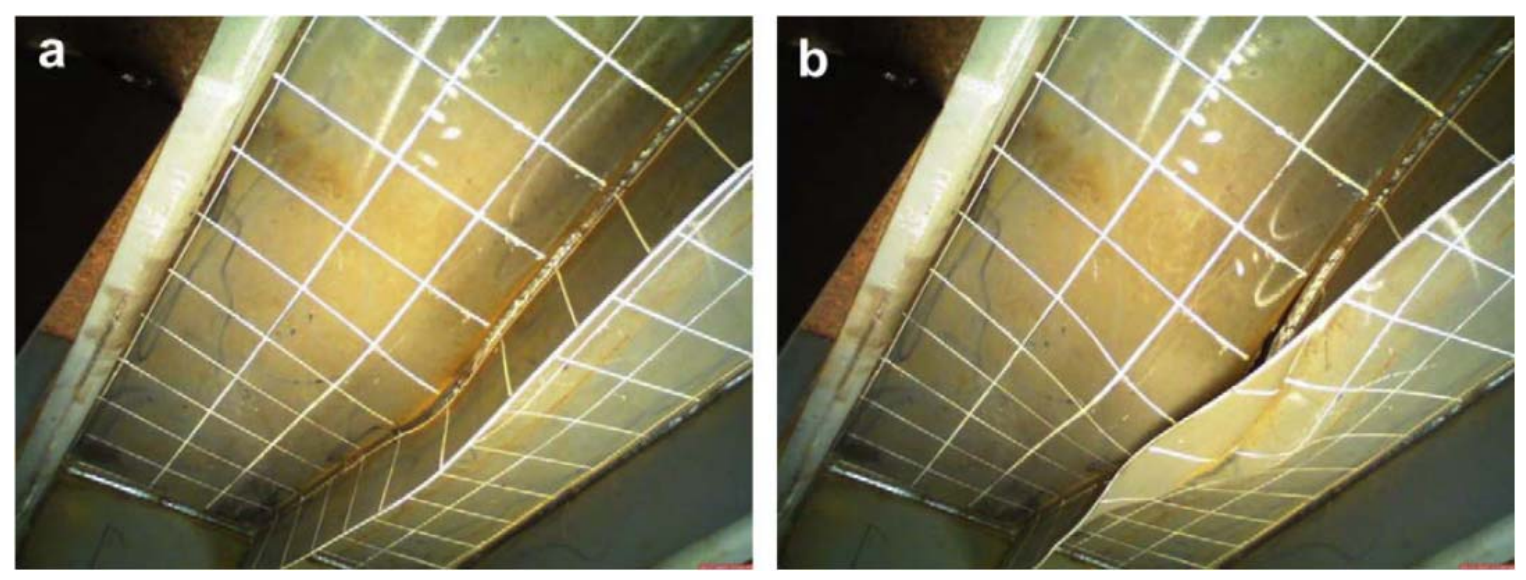

Figure 10 - Deformed shape of the stiffened plate: (a) before, and (b) after stiffener tripping and crack initiation 
Plate stretching is restrained by the friction between the plate and the indenter, which causes initial crack to occur away from the contact area. In addition, after stiffener tripping, the area directly under the indenter is dominated by nearly equi-biaxial stretching (the deviation from equi-biaxial state is caused by the difference in the length vs. width dimensions). The deformation zone where the plate loses contact with the indenter is close to plane strain condition. Based on the experimental data discussed in Section 2, the plane strain tension is associated with the lowest strain to fracture, which indicates that fracture should initiate near the location where the indenter and the plate lose contact. This is consistent with both the experimental observations and analysis conducted by Alsos et al. [1-2]. We also note that the crack stayed within the weld-line and did not branch off into the plate. As discussed earlier, this was almost certainly caused by the material property change caused by the welding process.

In the following subsections, analyses of the general behavior of the stiffened plate, including its fracture initiation and propagation are discussed. Both of the fracture modeling methodologies discussed in Section 3 were used in the analyses and their results will be discussed separately.

\section{Cohesive Zone Model}

The cohesive zone methodology in the current work uses discrete cohesive elements that connect the adjacent (initially coincident) finite element nodes on the two opposing sides of the anticipated crack path. This approach, while simple and efficient, requires the crack path to be assumed or known a-priori. In the general case, discrete cohesive elements could be used for every pair of nodes, as described by Xu and Needleman [73]. However, this is not practical for large-scale ductile fracture simulations due to high computational cost. A more elegant and possibly efficient solution could be developed based on the eXtended Finite Element framework (XFEM) [14], and/or the phantom node approach [61].

As discussed above, the crack initiated in the HAZ adjacent to the weld and propagated along the weld-line. This allows cohesive elements to be used only along the observed crack path, which significantly simplifies the analyses. We note however that the crack path is not always known apriori and often cannot be determined by simple 'engineering judgment'. In such cases, multiple crack paths would therefore have to be analyzed to determine the critical one. This points to a potential shortcoming of the cohesive zone methodology (as used in the current work) that limits its capability for true prediction of ductile fracture without prior knowledge of the observed experimental behavior. This will be further discussed in the later sections.

Significant differences exist in the level of deformation constraint, and therefore resistance to crack opening, along the anticipated path. We distinguish three separate 'zones' (shown in Figure 11) that are associated with different levels of fracture energy: Zone 1 - biaxial tension condition, Zone 2 - approximately plane strain tensions condition and Zone 3 - approximately uniaxial tension condition. These zones are associated with different levels of stress triaxiality, as well as straining in the direction parallel to the crack, which results in significant variation of the fracture energy among the zones. Assuming that the interpretation of the general state of stress in all the zones is correct, the fracture energy should be the lowest in Zone 2 and highest in Zone 3, with Zone 1 falling in between. In Zones 1 and 2, the effective fracture strain will be significantly smaller than measured in the uniaxial tensile test, shown in Figure 9. Furthermore, the onset of sheet-like necking should occur at a lower strain level in Zone 2 than in Zones 1 and 3. 


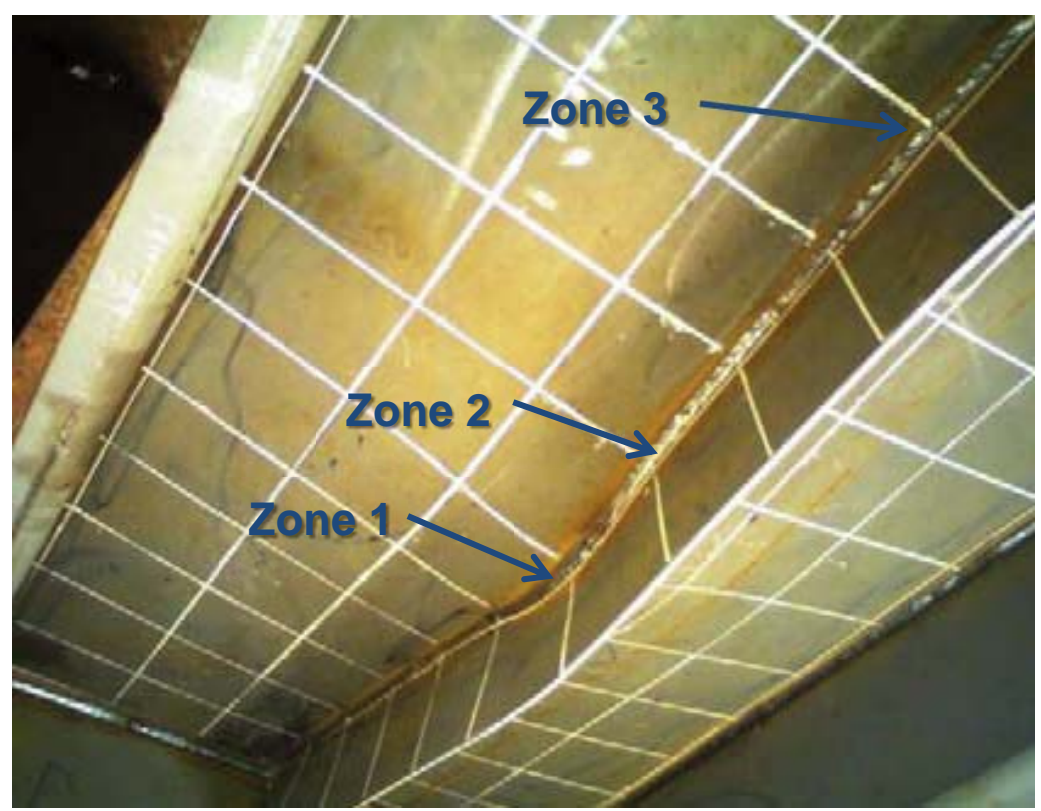

Figure 11 - Zones along the crack path with different fracture energy levels [1]

To accurately simulate crack initiation and propagation, the traction-separation relationship governing the cohesive zones must account for the different fracture energies in the three distinct zones (the material behavior until the onset of necking is represented by standard shell elements). Three separate relationships are therefore employed in the simulations conducted here, with different amounts of energies. Considering that plane strain and equibiaxial stress-strain curves were not available, these relationships were calibrated by adjusting the amount of energy under the curve (for all three zones) until an acceptable agreement between the test results and the analysis was obtained. In all cases, a tri-linear functional dependence was assumed. The final traction-separation relationships in the three zones of interest are shown in Figure 12. As will be discussed further later, it remains for future work to devise a traction-separation relation that incorporates a functional dependence on the local state of biaxiality such that one would not have to resort to the identification of biaxiality zones. 


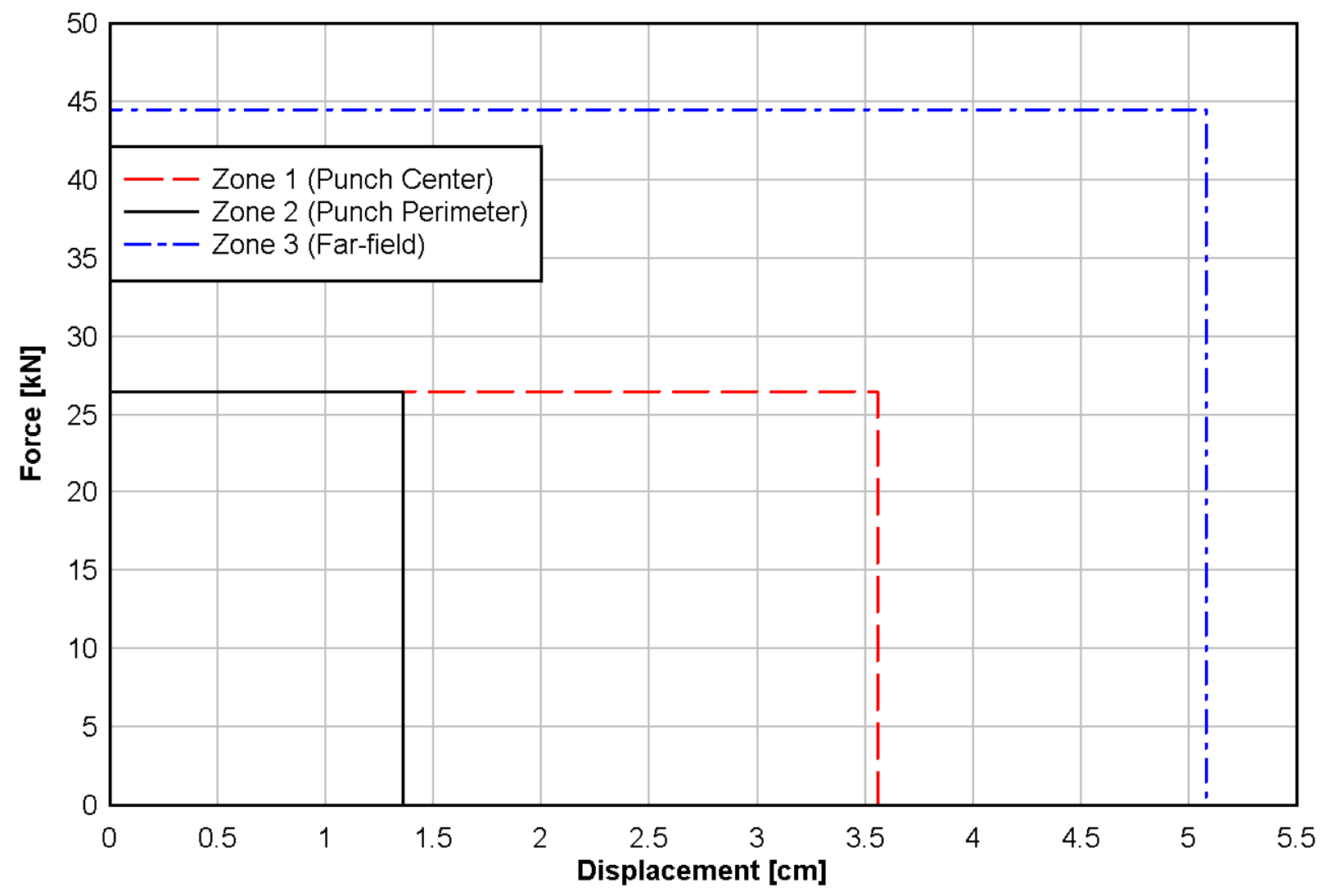

Figure 12 - Traction-separation relationships in three different cohesive zones along the crack path (stiffened 1FB steel plate)

As expected, the cohesive energy is the lowest in Zone 2, dominated by approximately plane strain condition. Significant energy increase is observed in Zone 1 (approximately in biaxial tension), and a further increase in Zone 3 (approximately in-plane tension). Considerable increase of both energy and peak traction is observed in Zone 3. It is possible that similar result could have been obtained with larger increase of energy in Zone 3, while keeping peak traction on the same level as in Zones 1 and 2. Nevertheless, the general relationship between the fracture energies and fracture strains in different zones is consistent with previously postulated general states of stress in these regions. As previously indicated, the analysis results showed that the shape of the traction-separation relationships was generally of little significance (for large-scale simulations).

The simulations were conducted using a uniform mesh of quadrilateral, non-layered shell elements $(\sim 1.3 \mathrm{~cm})$. One-dimensional spring-type elements used as cohesive elements were introduced along the potential crack path following the weld. The progression of fracture obtained by finite element analysis with embedded cohesive zones is shown with equivalent plastic strain contours in Figure 13. 

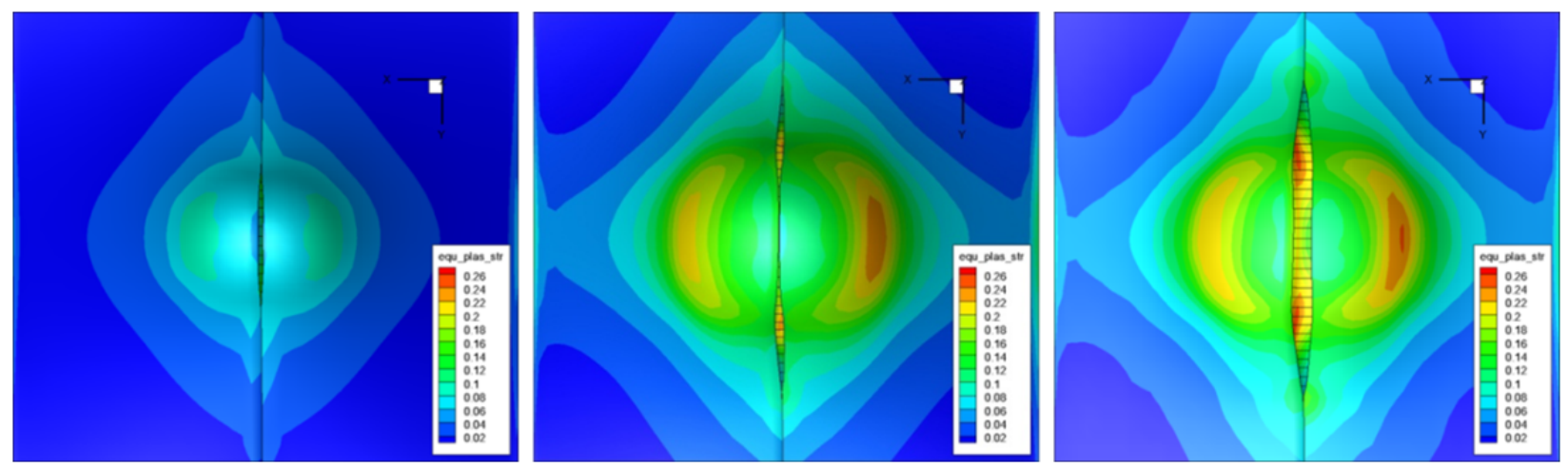

Figure 13 - Equivalent plastic strain contours during crack propagation (left to right) - stiffened plate (1-FB) simulation using the cohesive zone model

Close investigation of the deformation and strain patterns in Figure 13 shows that initially the cohesive elements in the center (Zone 1) of the plate begin to elongate slightly but do not reach sufficient separation to open the crack (left image). As the indenter penetrates further (center image), a "plane strain ring" (Zone 2) with large plastic strain begins to form around the perimeter of the indenter and the cohesive elements along the weld in this region elongate to the point of crack initiation. Finally, as the indenter continues to penetrate further (right image), the crack propagates through the central cohesive elements (Zone 1) and further away from the center of the plate (Zone 3). This fracture initiation and propagation pattern is consistent with the experimental observations.

A qualitative comparison of the analysis and test results is shown in Figure 14. The left image is a photograph of the underside of the plate after fracture, while the right image shows the corresponding simulation results using the cohesive zone modeling approach. In both cases, the stiffener buckles in approximately the same mode and the final crack is very similar in length to the crack observed in the experiment. The qualitative comparison of the crack initiation and propagation, as well as the general plate behavior indicates very good agreement of the simulation with the experimental observation.
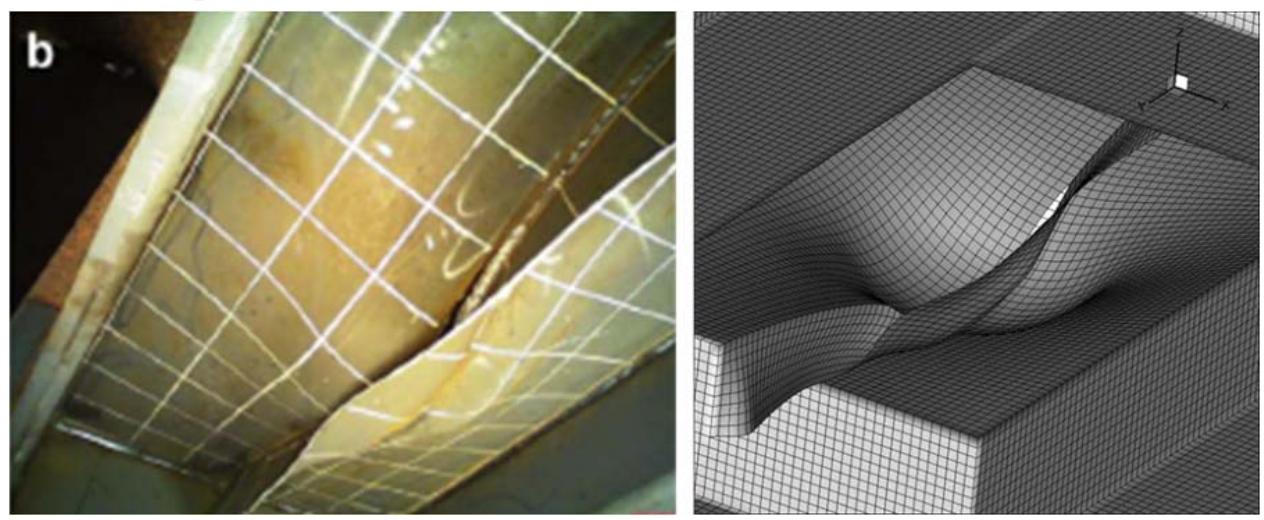

Figure 14 - Deformed and cracked plate specimen (left) [1], and corresponding results of the finite element simulation with the cohesive zone model (right) - stiffened plate (1-FB)

The comparison of the measured and calculated global force-displacement relationship is shown in Figure 15. 


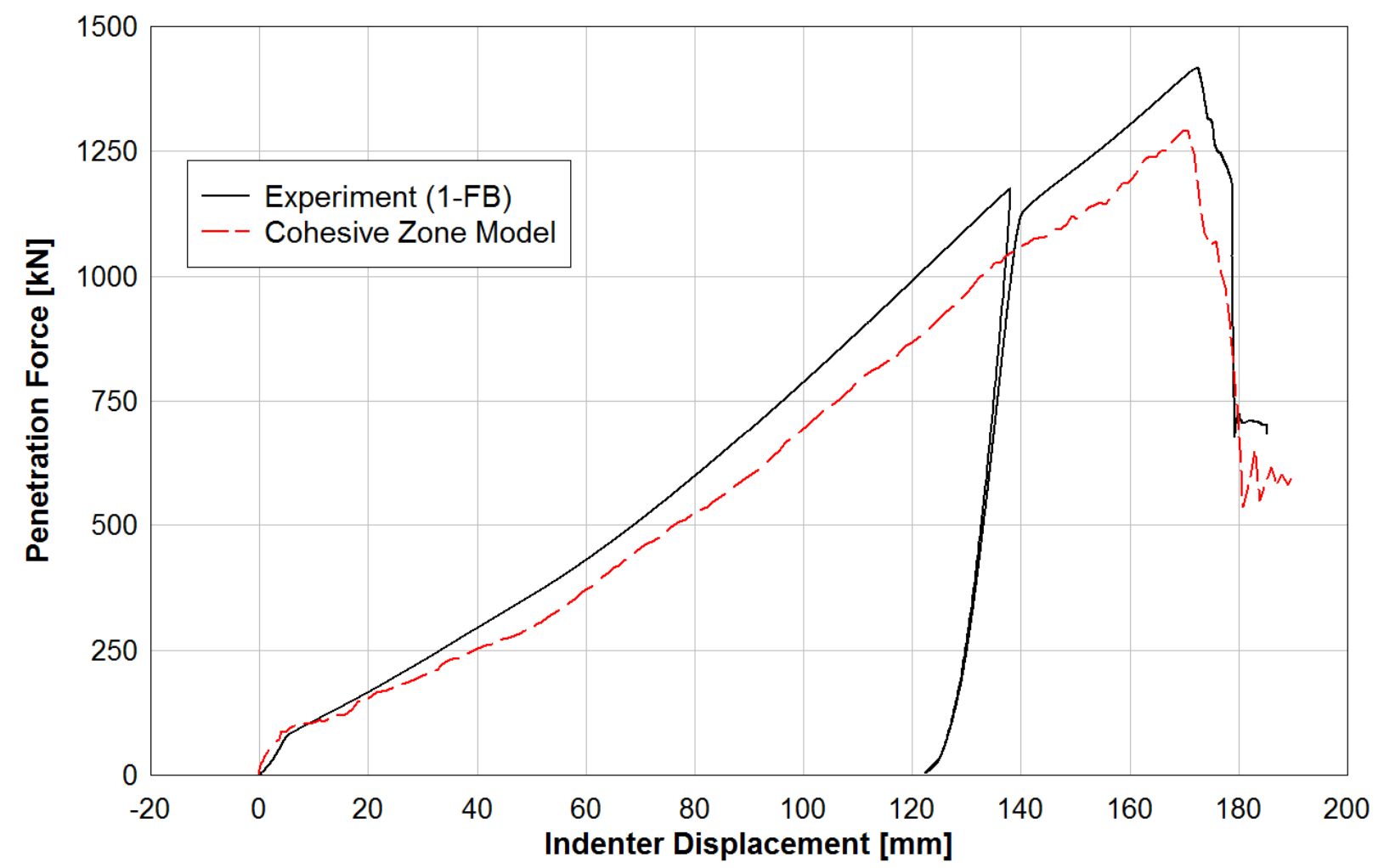

Figure 15 - Experimentally measured and calculated force-displacement relationship for penetration of the stiffened plate

The cohesive zone simulation methodology provides a good and reliable approximation of the measured behavior, including the post-critical equilibrium path. The observed difference in the slope of the curves is caused by inaccuracies in accounting for friction between the indenter and the plate, which was approximated using a standard Coulomb friction model with a constant coefficient of 0.3. This discrepancy is consistent with observations made by Alsos [2]. Both quantitative and qualitative comparison of the test and simulation results show very good agreement, validating the assumptions and indicating that the proposed cohesive zone approach for ductile fracture analysis is capable of delivering close approximations.

Close agreement between the measured and simulated behavior shows the importance of stress triaxiality as well as multiaxial straining. Significant differences in the levels of strain energy dissipated in the fracture process exist along the crack path, as shown by the test results. Reliable simulation methodologies must account for these differences to correctly approximate the fracture process and the global response of the ductile structure undergoing extensive tearing.

We note that the traction-separation relationships governing the cohesive zones have been 'manually' calibrated to account for the aforementioned differences in available fracture energy and match the results of the experiment. While this approach offers important insights into the investigated problem, in most real engineering problems involving ductile fracture it will not be easy to identify zone of differing biaxiality beforehand, as has been done here. The true predictive methodology must introduce a traction-separation law that embeds the effects of multiaxial stress such that the fracture energy is adjusted based on the local state of stress (and/or possibly strain) near the crack tip. Tvergaard and Hutchinson [64] developed a strain dependent 
cohesive zone methodology for ductile fracture simulation. More recently, Anvari et al. [3] proposed a triaxiality-dependent cohesive zone methodology where the traction separation relationship depends on the stress triaxiality. These methods are currently under investigation by the authors.

All analyses were conducted with a uniform Cartesian mesh of $1.2 \mathrm{~cm}$ shell elements. Although an extensive mesh convergence study with a variety of different meshes was not conducted, additional analyses indicated that the results were not sensitive to the element size. Recalibration of the traction-separations is, however, required in each of the three cohesive zones (although this can be automated).

\section{Phenomenological Damage Model}

Penetration of the stiffened plate was also investigated using the phenomenological damage model, which explicitly accounts for the effects of stress triaxiality. Therefore, this model can correctly approximate the variation of the fracture energy in the three different zones shown in Figure 11, as long as the model is accurately calibrated for uniaxial and multi-axial tensile conditions.

As in the case of the cohesive zone methodology, the simulations were conducted using a uniform mesh of quadrilateral, non-layered shell elements $(\sim 1.3 \mathrm{~cm})$ with Mindlin-Reissner kinematics and stress resultant formulation. A single line of $0.5 \times 1.3 \mathrm{~cm}$ shell elements with softening behavior governed by the phenomenological damage model (Section 3.2) were used on each side of the stiffener, as shown in Figure 16. The remaining elements employed a standard J2-type plasticity model which, expressed in terms of stress resultants, takes the form of the Iliushin yield criterion [33]. Note that if the crack path were not known a priori, the damage model could have been used for all elements in the plate - albeit at a greater computational cost.

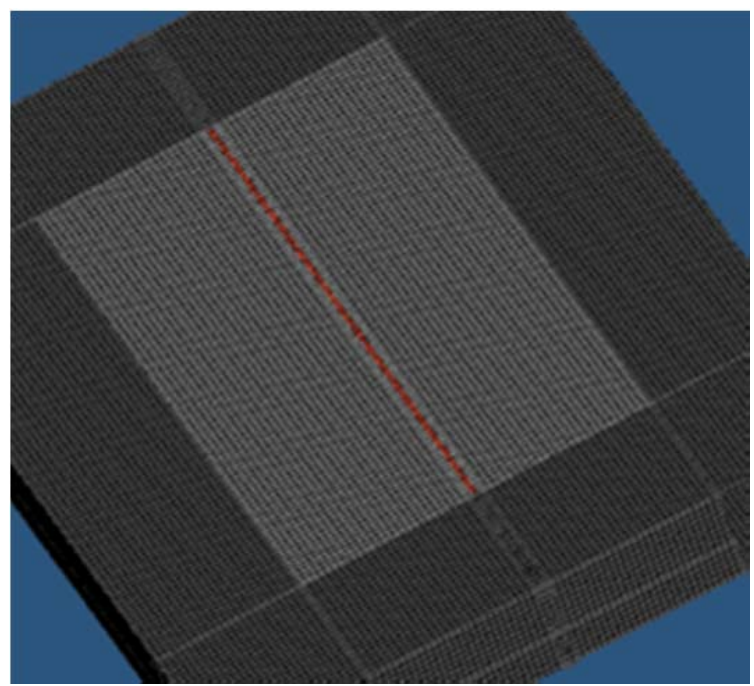

Figure 16 - Finite element mesh for simulation of the stiffened plate with the phenomenological damage model - red line shows elements with softening behavior

The initial calibration of the damage model was performed based on the uniaxial tensile tests performed by Alsos et al. [1,2], as already discussed in Section 3.2. The forming limit diagram for steel were used to determine the reduction of the fracture energy in biaxial tension (comparing to uniaxial tension). A $5 \mathrm{~cm}$ gauge length was assumed for regularization (Woelke 
and Abboud [68]). In absence of any information about the properties of the weld material, the weld properties were assumed to be the same as the parent metal. After initial calibration, the finite element model of the penetrated plate was exercised several times and the results compared with the measured response. Only minor recalibration of the model parameters was necessary to achieve a close correlation between the measured and simulated responses. The final calibrated engineering stress-strain curves for the phenomenological damage model, along with the values of the model parameters, are shown in Figure 17.

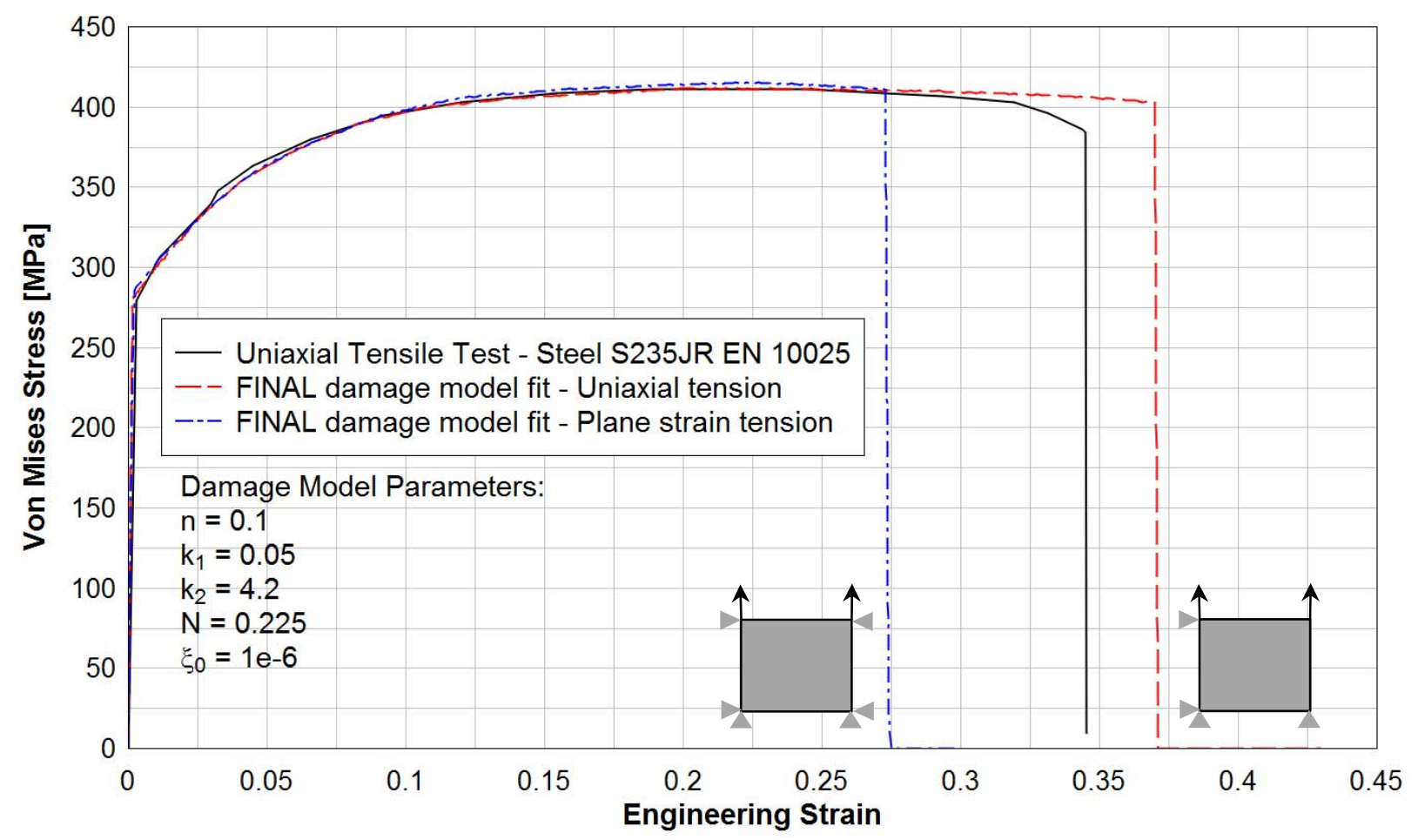

Figure 17 - Mild steel S235JR EN10025 uniaxial engineering tensile test data [1] and the corresponding final damage model calibration based on single element analyses; uniaxial tension and plane strain tension

The damage model stress-strain behavior shown in Figure 17 was used in the finite element analysis, with the results matching closely the measured response. Similarly to the initial calibration process (Section 3.2), both uniaxial and biaxial tension loading conditions were used to characterize the material behavior. As expected, the stress-strain curve obtained for plane strain tension has significantly reduced critical strain (comparing to uniaxial tension). The deformation of the plate in a penetration test indicates slightly larger ductility than indicated by the uniaxial tensile data (Figure 9) - possibly a result of material changes from welding. The discrepancy could also come from the fact that the gauge length used in the uniaxial test was unknown (assumed $5 \mathrm{~cm}$ ). Since the gauge length is the distance over which the deformation is assumed homogenous, as discussed by Woelke and Abboud [68], its variation leads to different critical fracture strain.

We note that, in the phenomenological damage model, the differences between material behavior in uniaxial and multiaxial tension are captured without intervention. The calibration process requires determining the values of the model parameters $n, k_{1}, k_{2}$, and $\xi_{0}$ from Eqs. [2] - [5] 
(characteristic for a given material), such that multiaxial tensile behavior is well represented for all relevant stress triaxiality levels (or biaxiality in the plane stress condition). This is in contrast with the cohesive zone approach, where manual recalibration had to be performed for all areas with significantly different triaxiality.

The analysis results agree very well with both the experimental data and the results of the cohesive zone model. Figure 18 provides two sequences of images showing evolution of the damage variable and equivalent plastic strain contours during initial deformation, crack initiation, and propagation. The crack initiation and propagation pattern, as well as the overall plate behavior is very similar to the results obtained with the cohesive zone model and, more importantly, the experimental observations.
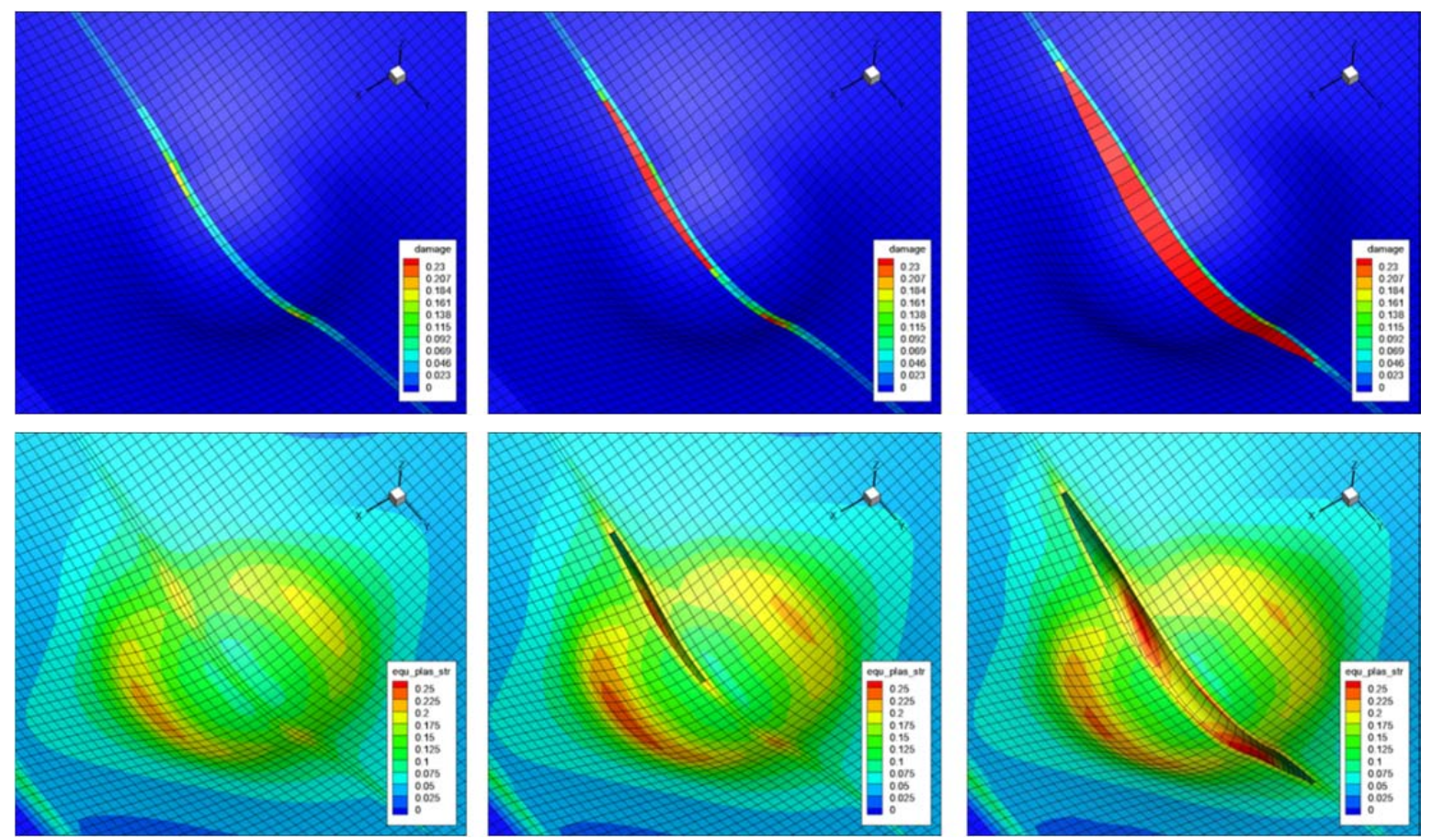

Figure 18 - Damage variable and equivalent plastic strain contour plots with crack initiation and propagation - analysis of the stiffened plate with the phenomenological damage model

As previously described, the damage elements were only used along the weld line, which limits the extent of computed damage variable to those elements. The contour plots show that the damage growth rate is highest around the perimeter of the punch, where the fracture initiates. Investigation of the equivalent plastic strain shows, however, that the level of plastic strain is actually highest at the punch perimeter in the short-span direction. This is caused by the fact that the closer support point provides additional constraint and higher strain levels. The fracture initiating in the weld was therefore most likely caused by the material inhomogeneity and residual stresses introduced by the welding process. An un-welded, extruded stiffened or unstiffened plate would most likely crack on the punch perimeter, along the direction perpendicular to the stiffener (in the shortest direction to the support).

The calculated force vs. indenter displacement relationship compares very well with the measured response (Figure 19), including the post-critical behavior, which validates the assumptions and implementation of the phenomenological damage model. The discrepancies between the curve slopes was, again, caused by inaccuracies in approximating friction between 
the indenter and the plate. This effect was also observed in the analysis conducted using the cohesive zone approach, as well as the numerical analysis conducted by Alsos [2].

As in the cohesive zone analysis, the damage model simulation shows the importance of stress triaxiality effects for fracture prediction. The level of triaxiality varies significantly along the crack, and this variation is strongly dependent on the boundary and initial conditions. Changes in the structural geometry (e.g. crack) will lead to significant changes in the local triaxiality levels which, in turn, strongly affects the ductility of the material.

\section{Comparison of Cohesive Zone and Damage Models}

Both of the analysis approaches have produced results that correlate closely with the experimental observations. The comparison of the experimental force-displacement relationship with the ones calculated using both approaches is given in Figure 19

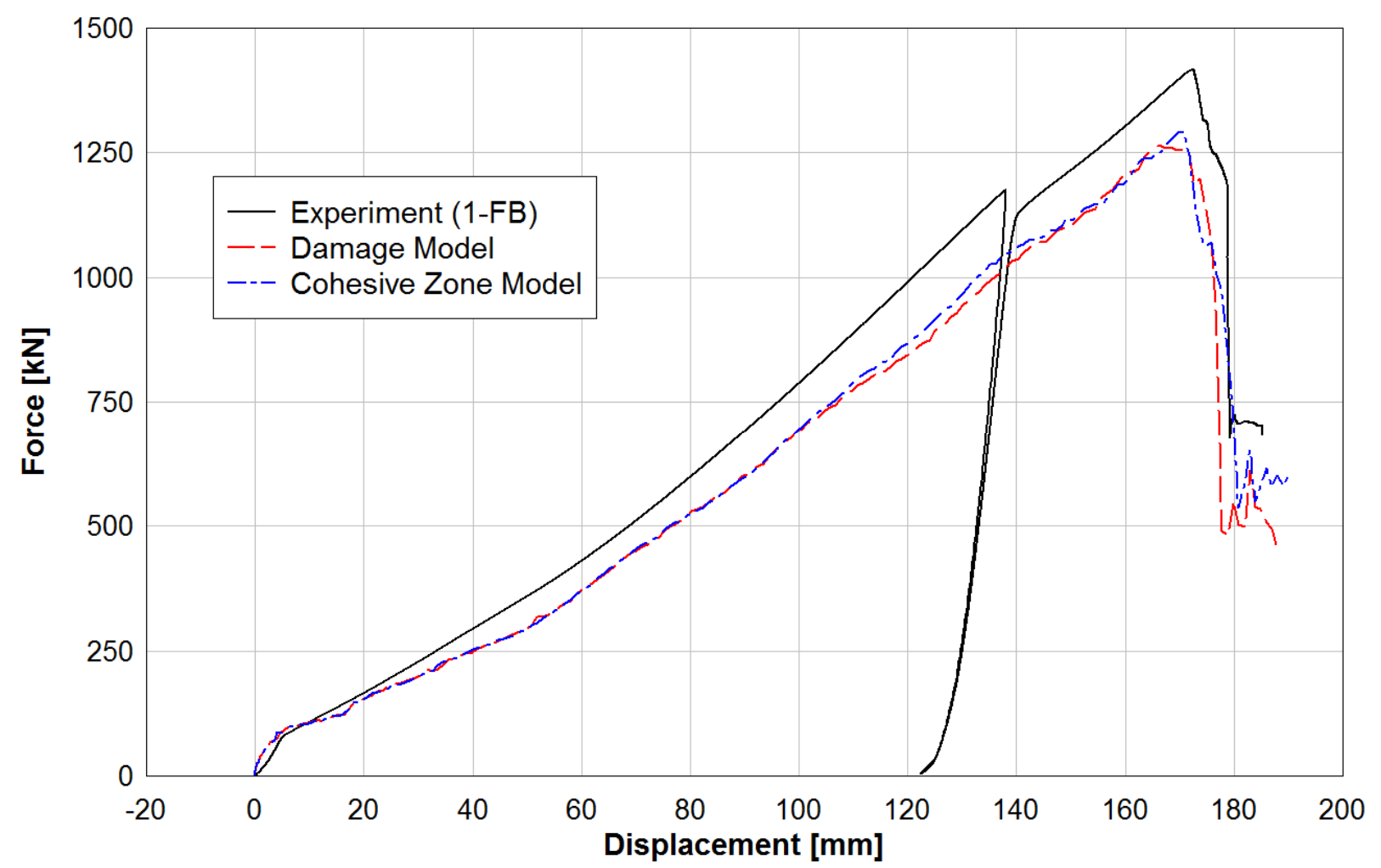

Figure 19. The curves obtained using the cohesive zone and phenomenological damage models are practically indistinguishable and match very well the experiment. The qualitative comparison discussed in the previous sections also indicated that both approaches reproduce the experimentally observed non-linear deformation and fracture patterns - and are in close agreement with one another in this regard. 


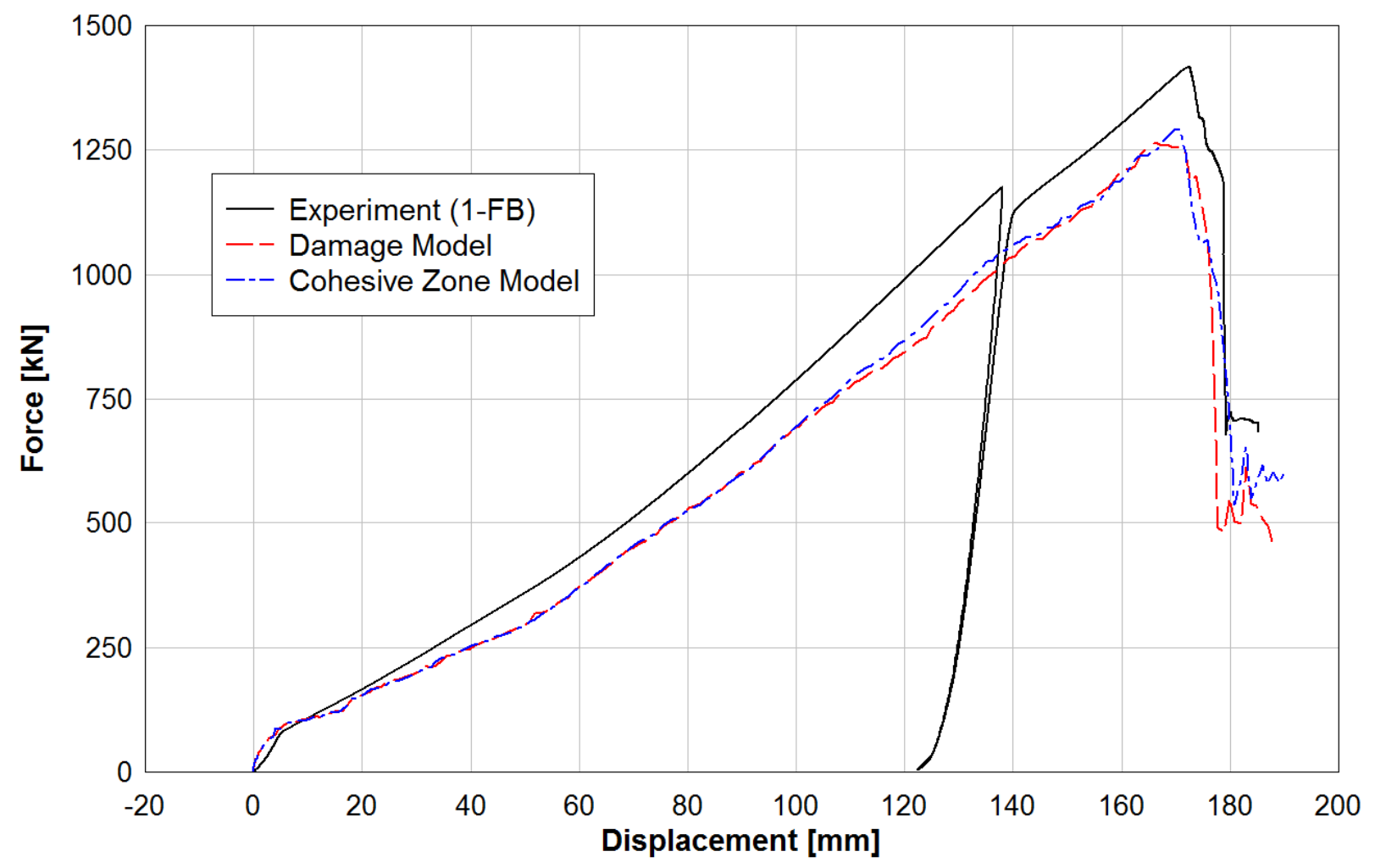

Figure 19 - Comparison of the measured force-displacement response with the results of the analyses conducted using both the cohesive zone and damage models

The key difference between the two fracture modeling approaches lies in their predictive capabilities. The traction-separation relationships governing the cohesive zones have been calibrated specifically to the large-scale penetration tests, which requires knowledge of the specimen behavior and fracture pattern. In contrast, the damage model calibration was performed based on coupon level tests, and then used for a large test analysis in a 'predictive mode' (minor recalibration was necessary to account for material property variation in the HAZ). While the influence of stress triaxiality is explicitly represented in the damage model, the cohesive zone approach adopted here requires that the cohesive elements be manually modified to account for this effect. In the current forms of the two modeling approaches, the damage model offers more flexibility and generality, making it more suitable for ductile fracture predictions. However, as already noted, the cohesive zone modeling and calibration could be improved by generating a family of triaxiality-dependent traction-separation relations calibrated with coupon level experimental data. This would make the cohesive zone approach more general, although not on the same level as the damage model, which not only captures the effect of triaxiality on fracture but also plasticity, through plasticity-damage coupling.

\subsection{Unstiffened plate (US)}

We investigate the unstiffened plate with no center-line weld in this section, which exhibited a less predictable fracture pattern. The deformed shape of the plate during testing is shown in Figure 20. 


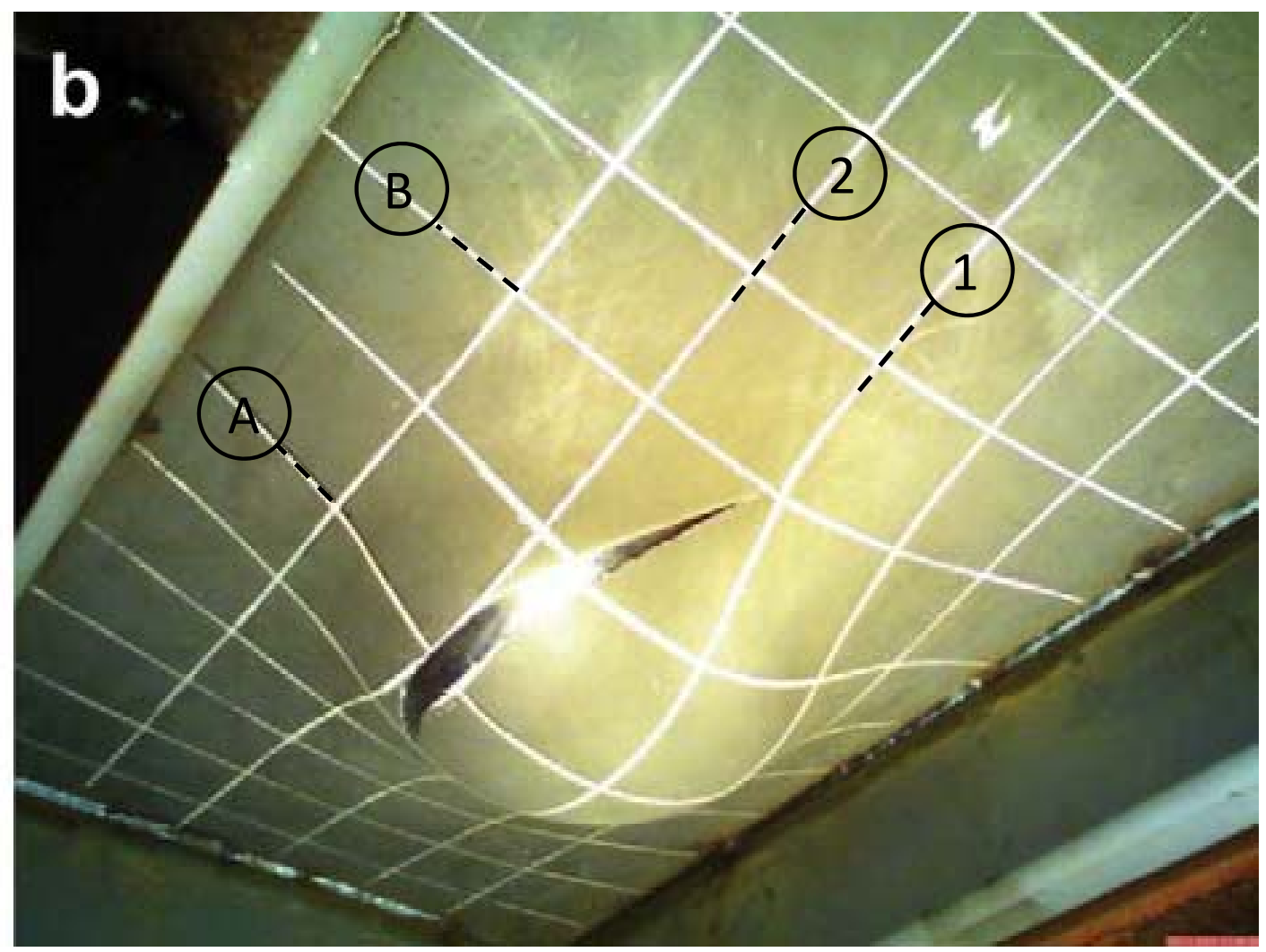

Figure 20 - Deformation and the fracture pattern of the unstiffened plate [1]

Considering the geometry of the plate, two possible planes of symmetry exist: along lines A and 1 - as shown in Figure 20. The intersection of these lines (A-1) is dominated by near equibiaxial stretching, similarly to Zone 1 in Figure 11. Similarly to the stiffened plate tests, the deformation is restrained by friction in the zone of contact with the indenter. As previously noted, friction was was approximated using a standard Coulomb friction model with a constant coefficient of 0.3. There are two locations along the presumed symmetry planes A and 1, where the plate loses contact with the indenter: A-2 and B-1. The stress/strain states at these locations are close to a plane strain condition. However, considering the smaller distance to the boundary along line A, location A-2 is more constrained than location B-1. The plane strain condition will therefore dominate at location A-2. Consequently, the crack initiated at this location (A-2) and followed the shape of the indenter, resulting in the characteristic annular crack shape seen in Figure 20.

Simulation of the annular fracture pattern using the cohesive zone methodology would require either a general mesh with discrete cohesive elements at every pair of nodes as described by Xu and Needleman [73] or by assuming the crack path follows the experimentally observed path. The former approach is computationally prohibitive for large-scale simulations, as previously discussed. The latter approach would require a finite element mesh that is specific to the problem, and, in any case, is not a predictive fracture approach. The unstiffened plate problem was therefore analyzed using the damage model only, with a uniform mesh of shell elements governed by the same constitutive model, explicitly accounting for variation of the failure strain as a function of stress triaxiality as previously detailed.

The damage model parameters were first calibrated to match the uniaxial tensile response of the steel material used to manufacture the large plate specimen. As in the case of the stiffened plate, 
the forming limit diagram for steel was used to determine the reduction of the fracture energy in biaxial tension. The results of the uniaxial tensile test, along with the calibrated material model obtained based on the analyses of the single shell element in uniaxial and plane strain tension are given in Figure 5.

The gauge length used during the uniaxial tension test was not reported, so it was assumed to be $5 \mathrm{~cm}$. The initial calibration followed very closely the uniaxial tensile test results, as shown in Figure 5. Analysis of the penetration led to a minor recalibration of the material parameters, which gave the uniaxial response given by the dashed line to the right of the test result. We note that the initial and final values of the model parameters are very close, which indicates robustness of the approach.

A Cartesian rectangular grid with $1.5 \mathrm{~cm}$ elements was used. Although the Cartesian mesh of relatively large elements is not ideal for simulation of the annular fracture patterns, it was chosen to demonstrate the mesh objectivity of the method and avoid meshing the component based on a known solution. A reliable fracture prediction methodology for ships and other large-scale structures requires that accurate results are obtained based on a general finite element model used for multiple analyses with different loading conditions (i.e. the FE mesh should not be catered to each particular solution or loading scenario).

The deformed shape and the fracture pattern obtained through analysis using the Cartesian grid of shell elements with the phenomenological damage model and the experimentally observed fracture pattern are shown in Figure 21.

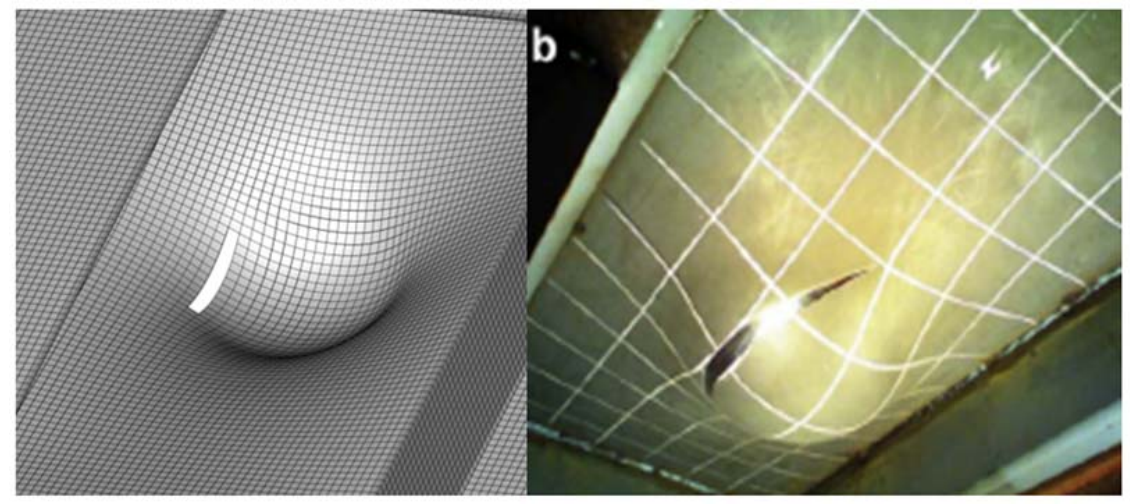

Figure 21 - Deformed shape and fracture pattern of the unstiffened steel plate obtained through rectangular mesh analysis and experiment [1]

The peak penetration resistance of the plate was correctly approximated (Figure 23), indicating that fracture initiation was correctly represented. As expected, the elements used in the analyses are too large to accurately represent the crack propagation pattern following the shape of the indenter. However, the annular damage and equivalent plastic strain patterns were correctly realized by the analysis, as shown in Figure 22. 

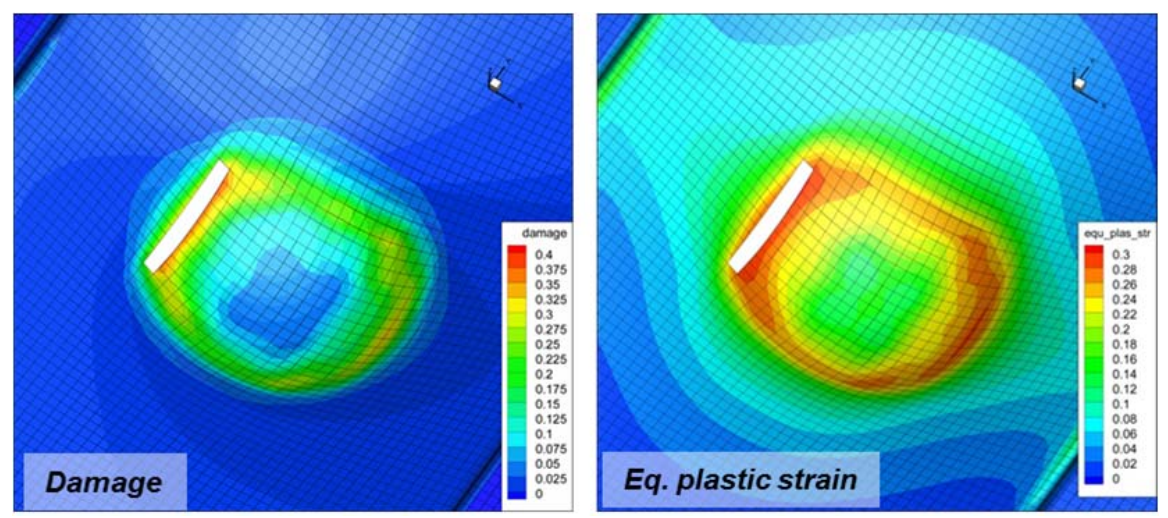

Figure 22 - Damage and equivalent plastic strain contours plotted on the deformed shape of the unstiffened plate subjected to penetration - rectangular mesh with straight crack line

Equally importantly, the calculated global indenter force-displacement relationship closely matches the measured response, including the post-peak behavior, as shown in Figure 23.

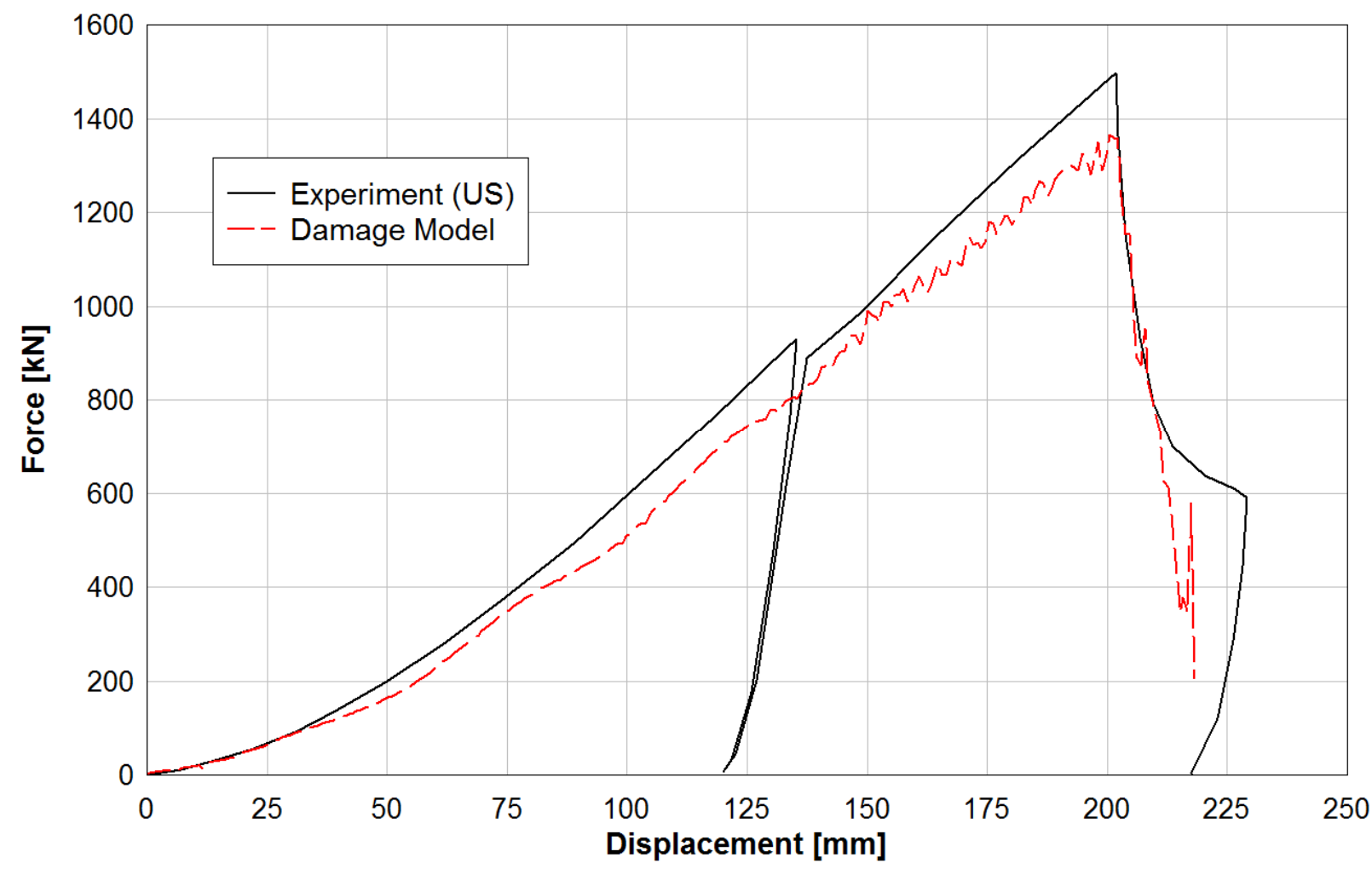

Figure 23 - Calculated (Cartesian grid) and measured global force-displacement relationship for the unstiffened plate

While the global response of the plate is accurately approximated by the damage model with Cartesian mesh, the overall fracture pattern differs from the observed pattern. To improve the quality of the results, we also considered a circular mesh that follows the shape of the indenter. This mesh allows the crack to propagate following the annular damage contours - effectively capturing the experimentally observed fracture path as shown in Figure 24 and Figure 25. 

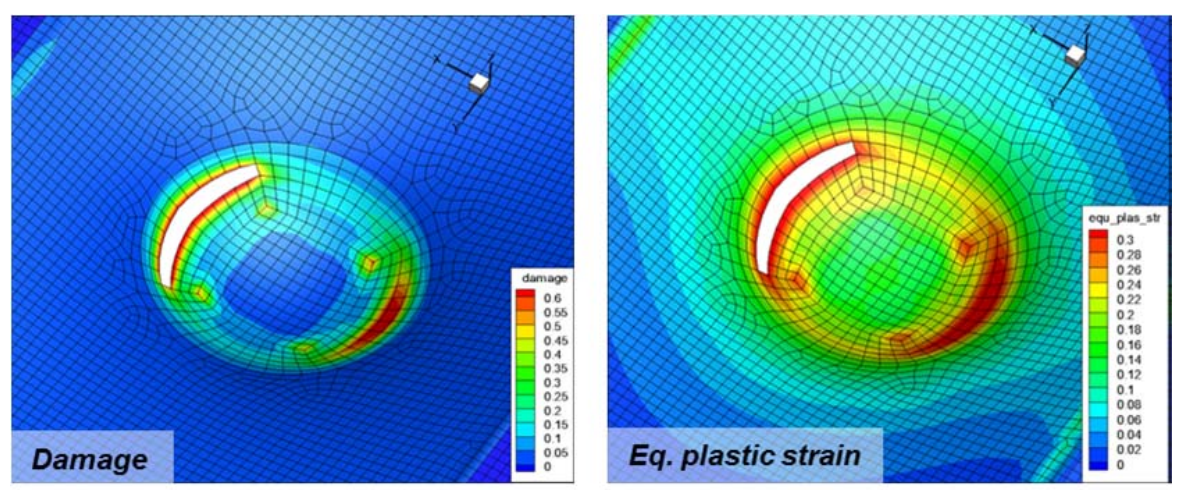

Figure 24 - Damage and equivalent plastic strain contours plotted on the deformed shape of the unstiffened plate subjected to penetration - circular mesh following the indenter shape

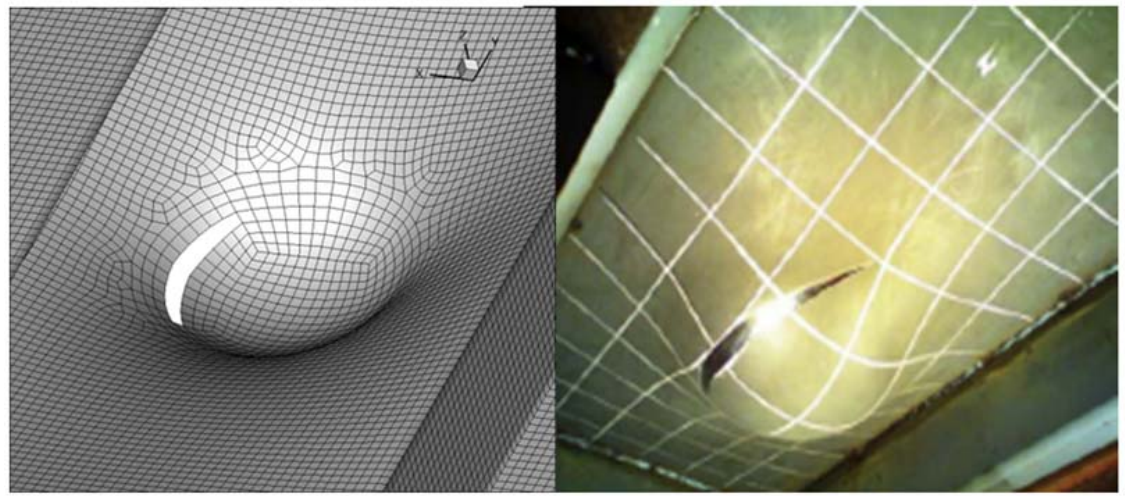

Figure 25 - Deformed shape and fracture pattern of the unstiffened steel plate obtained through circular mesh analysis and experiment [1]

The experimental indenter force-displacement relationship is also accurately reproduced with the circular mesh. The analyses results obtained from both the rectangular and the circular mesh are cross-plotted against the experimentally measured force-displacement curve in Figure 26. There is little difference between the results using the two different meshes except in the post peak behavior, which is indicative of the level of mesh objectivity using the phenomenological damage model. Only a minor recalibration of the model parameters was conducted when converting from the rectangular to the circular mesh. The critical damage level at fracture was increased from $\xi_{\text {crit }}=0.22$ in the case of the rectangular mesh to $\xi_{\text {crit }}=0.40$ in the case of the circular mesh (all the other parameters remained unchanged). We note that damage grows exponentially in the phase of deformation directly preceding fracture, which means that the increase of critical damage level from $\xi_{\text {crit }}=0.22$ to $\xi_{\text {crit }}=0.40$ corresponds to relatively small increase of strain at fracture - from $\varepsilon_{f}=0.37$ to $\varepsilon_{f}=0.41$. 


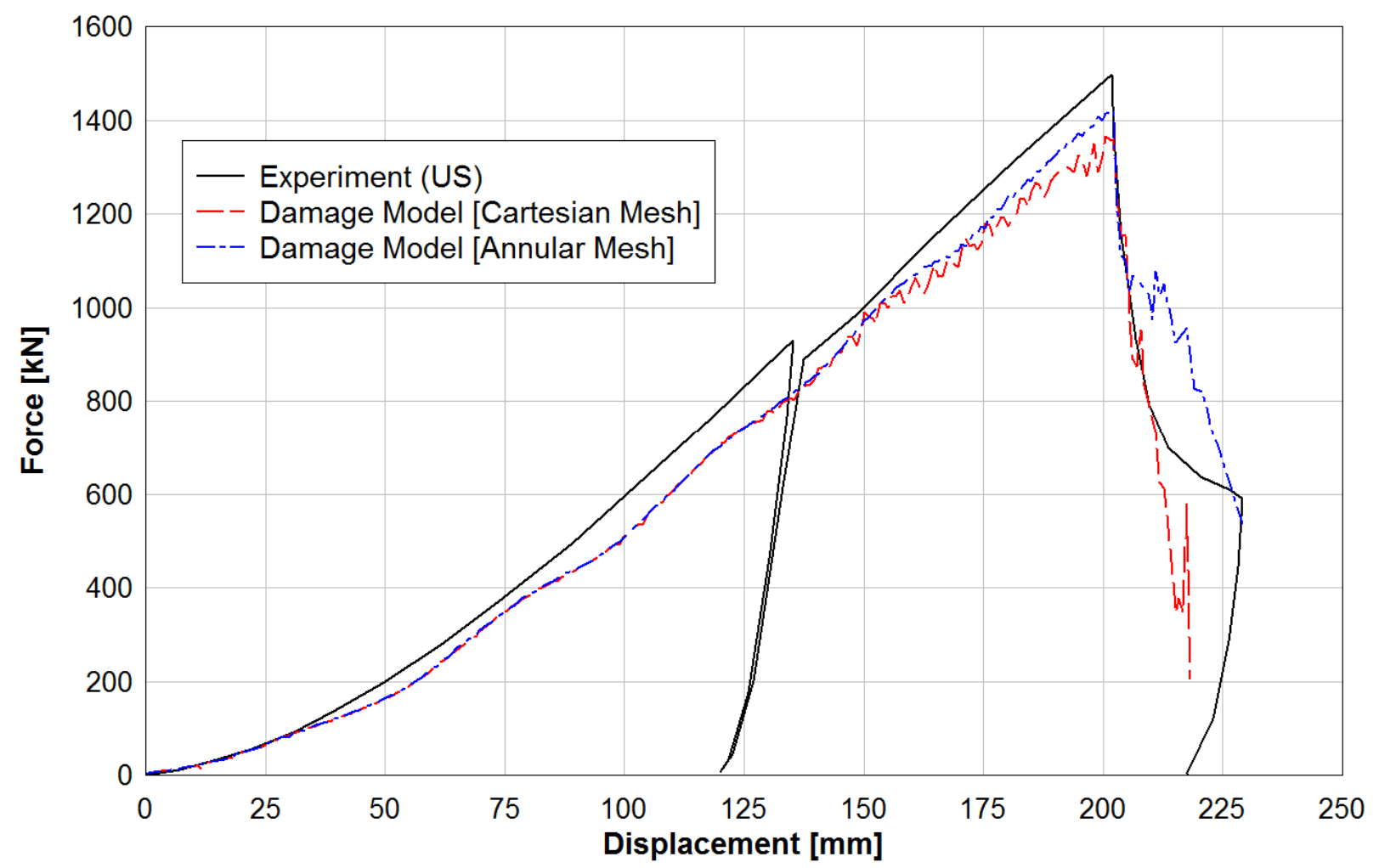

Figure 26 - Global force-displacement relationship obtained through analyses with rectangular and circular mesh vs. measured response - unstiffened plate

While a full mesh convergence study was not performed for the current problem (based on multiple sizes of the elements), such study was performed based on the mode I tearing of an aluminum plate tested by Simonsen and Tornqvist [58]. The details of this study are discussed in a separate paper, currently under preparation [60]. Based on the analysis discussed here, significant mesh dependency of the solution was not observed.

The results for the unstiffened plate analysis show, once again, the importance of the multiaxial stress and strain states for fracture initiation and propagation. The results also clearly indicate that the fracture simulation methodology based on the phenomenological damage model can successfully predict arbitrary fracture patterns, both qualitatively and quantitatively. We emphasize that all simulations presented here were performed with relatively large structural shell elements (4-10 times the plate thickness $t=0.5 \mathrm{~cm})$, which is of high significance for ships and other large-scale structural applications.

\section{Summary and Discussion}

Two alternative simulation approaches for fracture analysis under multi-axial loading conditions have been discussed in this paper: cohesive zone and phenomenological damage models [68]. Both methodologies were carefully investigated based on idealized ship grounding experiments. The experiments involved large penetration of stiffened and unstiffened steel plates causing ductile fracture, dominated by biaxial stretching. Both of the analysis approaches produced results that correlate very closely with the experimental observations. The fracture patterns and global force-displacement responses obtained from the analyses closely matched the experimental observations. 
The fundamental concepts of the two investigated approaches differ significantly from the point of view of theoretical considerations and finite element implementation. The traction-separation relationship (or cohesive law), which represents the complicated plate deformation behavior at the crack tip after the onset of necking, governs the cohesive zone model. Discrete finite elements are used to allow crack opening along the predefined crack paths. While the need for a presumption of the crack path limits significantly the generality of the method, it also makes it very simple and efficient. This is of particular value for analysis of weld fractures, especially in aluminum with undermatched welds [60].

The form of the cohesive zone used here requires 'manual' calibration of the cohesive energy to reproduce the experimentally observed behavior associated with different level of stress biaxiality. This approach can provide extremely valuable insight, since it allows accurate determination of the cohesive energy (which is related to effective tearing toughness) depending on the multiaxial stress and strain state. However, this approach is not adequate for predictive analyses, unless the intrinsic dependence on the stress state and level of constraint is introduced into the cohesive traction-separation law. A triaxiality-dependent cohesive zone methodology has recently been developed by Anvari et al. [3]. This approach has the potential for significantly improving the predictive capability of the cohesive zone model, and is currently being investigated.

The phenomenological damage model, on the other hand, is calibrated based on coupon level uniaxial and biaxial tensile tests (or uniaxial test and analytical solutions based on the forming limit for biaxial tension). The calibration process is therefore specific to material only, and not the considered problem, assuming plate-like tearing failures. This makes the damage model significantly more general and adequate for predictive analyses. In addition, the damage model is typically used with a uniform mesh (with all elements being governed by the same constitutive equations), which does not require knowledge of the crack initiation location or its path. The generality of the damage model comes at a price of slightly reduced computational efficiency.

Despite the substantial differences in the fundamental concepts underlying the two approaches, the agreement between the results obtained is remarkably close. Both models effectively reproduce the experimentally observed behavior.

Another key observation that can be made based on the plate penetration problems, is the importance of both stress and strain distribution along the crack path. Recent renewal of the interest in ductile fracture mechanics has led to a better understanding of the influence of both stress triaxiality and a second measure of the stress state, the Lode parameter, on ductility. The sheet forming limits as well as biaxial tensile data for sheets (Section 2) developed for the automotive industry clearly indicate that the plane-strain condition is more critical than equibiaxial or uniaxial tension. This is also clearly visible in the idealized ship grounding experiments investigated here. The important point to note is that the equibiaxial tension is associated with higher level of stress triaxiality ( $2 / 3$ before crack opening) than plane-strain $(1 / \sqrt{3})$. The strain to failure in thin sheets is, however, lower in plane-strain condition. The investigations conducted here indicate that the effects of the Lode parameter, and possibly straining parallel and perpendicular to the crack, deserve as much attention as the effect of stress triaxiality. The influence of Lode parameter was included in the Gurson model modified by Nahshon and Hutchinson [47]. Bai and Wierzbicki [6] also accounted for the Lode angle effects in their extension of the Mohr-Coulomb model. The effects of strain distribution on fracture 
energy were investigated by Tvergaard and Hutchinson in 1996 [64]. These effects are also currently under investigation by the authors.

\section{Acknowledgement:}

The support of the Office of Naval Research: Dr. Paul Hess and Dr. Ken Nahshon (Contract No. N00014-10-M-0252) is gratefully acknowledged.

\section{References}

1. Alsos, H. S., Amdahl, J., \& Hopperstad, O. S. (2009), On the resistance to penetration of stiffened plates, Part I - Experiments. Int. J. Impact Eng., 799-807.

2. Alsos, H. S., Amdahl, J., \& Hopperstad, O. S. (2009). On the resistance to penetration of stiffened plates, Part II: Numerical analysis. Int. J. of Impact Eng., 875-887.

3. Anvari, M., Scheider, I., Thaulow, C., (2006), Simulation of dynamic ductile crack growth using strain-rate and triaxiality-dependent cohesive elements; Engineering Fracture Mechanics, 73, 2210-2228

4. Atkatsh, R.S., Baron, M.L \& Bieniek, M.P. (1980). A Finite Difference Variational Method for Bending of Plates. Computers \& Structures, 11, 573-577

5. Atkatsh, R.S., Bieniek, M.P. and Sandler, I.S. (1983). Theory of Viscoplastic Shells for Dynamic Response. J. of Applied Mechanics, 50, 131-136.

6. Bai, Y. and Wierzbicki, T., (2008), A new model of metal plasticity and fracture with pressure and Lode dependence. Int. J. Plasticity 24, 1071-1096.

7. Bao, Y., Wierzbicki, T., (2004), On fracture locus in the equivalent strain and stress triaxiality space. Int. J. Mech. Sci. 46 (81), 81-98.

8. Barrenblatt, G. I. (1962). The mathematical theory of equilibrium crack in brittle fracture. Adv. Appl. Mech, 55-129.

9. Barsoum, I. and Faleskog, J., (2007), Rupture in combined tension and shear: Experiments; Int. J. Solids Struct. 44, 1768-1786.

10. Barsoum, I., Faleskog, J., (2011a), Micromechanical analysis on the influence of the Lode parameter on void growth and coalescence. Int. J. Solids Struct. 48, 925-938.

11. Barsoum, I., Faleskog, J., (2011b), Tension-torsion fracture experiments-Part I: experiments and an evaluation procedure for the effective plastic strain. (to be published)

12. Beese, A. M., Luo M., Li, Y., Bai, Y., Wierzbicki, T, (2010), Partially coupled anisotropic fracture model for aluminum sheets; Eng. Fracture Mech., 77, 7; 1128-1152

13. Belytschko, T. and Tsay, C.S. (1983) "A stabilization procedure for the quadrilateral plate element with one-point quadrature”; Int. J. Num. Meth. Eng.; 19; 405419

14. Belytschko, T., Loehnert, S., and Song, J.H., (2008), Multiscale aggregating discontinuities: A method for circumventing loss of material stability, Int. J. Num. Meth. Eng.; 73:869-894

15. Belytschko, T., Chen, H., Xu, J., and Zi, G., (2003), ” Dynamic crack propagation based on loss of hyperbolicity and a new discontinuous enrichment”, IJNME; Vol. 58; pp. 1873-1905

16. Crisfield M. A. (1981) Finite element analysis for combined material and geometric nonlinearities. In Nonlinear Finite Element Analysis in Structural Mechanics, Wunderlich et al. (eds). Springer-Verlag: New York; 325-338.

17. Dugdale, D. S. (1960). Yielding of steel sheets containing slits. J. Mech. Phys. Solids, 100-104 
18. Feyel F. (2003), A multilevel finite element method (FE2) to describe the response of highly non-linear structures using generalized continua. Computer Meth.in App. Mech. and Eng.; 192; 3233-3244

19. Fish, J. and Shek, K. (2000), Multiscale analysis of large-scale nonlinear structures and materials. Int. J. Comp. Civil and Structural Engineering, 1(1), 79-90

20. Fleck, N.A., Hutchinson, J.W., (1986). Proc. Roy. Soc. London, A407, 435-458.

21. Flugge, W. (1960). Stresses in Shells. Springer, New York.

22. Fractography; ASM Handbook Vol. 12, ASM International

23. Giagmouris, T., Kyriakides, S., Korkolis, Y.P., Lee, L.-H. (2010) On the localization and failure in aluminum shells due to crushing induced bending and tension; Int. J. Solids and Structures, 47, 2680-2692

24. Giovanola, J. H. (1988). Adiabatic shear banding under pure shear loading. Mech. of Mater., 7, 59-87.

25. Gurson, A.L. (1975). Plastic flow and fracture behavior of ductile materials incorporating void nucleation, growth and interaction, $\mathrm{PhD}$ Thesis, Brown University.

26. Gurson, A.L. (1977). Continuum theory of ductile rapture by void nucleation and growth - Part I - Yield criteria and flow rules for porous ductile media. J.Eng. Mater. Technology, 99, 2-15.

27. Hadamard, J. (1923), Lectures on Cauchy's Problem in Linear Partial Differential Equations, Dover Publications, ISBN-10: 0486495493

28. Hancock, J.W., Mackenzie, A.C., (1976). On the mechanisms of ductile fracture in highstrength steels subject to multi-axial stress-states. J. Mech. Phys. Solids 24, 147-160

29. Hickey W.F., Ghahremaninezhad A. and Ravi-Chandar K. (2010), Characterization of Ductile Failure [Report]; Arlington, VA : ONR - MURI/FNC Review, 2010

30. Hillerborg, A., Modeer, M., Peterson, P. (1976) "Analysis of crack formation and crack growth in concrete by means of fracture mechanics and finite elements"; Cement Concrete Res., 6,773-782.

31. Hutchinson, J.W., Tvergaard, V., (1989), Softening Due to Void Nucleation in Metals. Fracture Mechanics: Perspectives and Directions (20th Symposium), ASTM STP 1020, edited by R. P. Wei and R. P. Gangloff, 61-83.

32. Hutchinson, J.W., (2010), Private communications.

33. Iliushin, A.A. (1956) Plastichnost, Gostekhizdat, Moscow.

34. Johnson, G.R., Cook, W.H., (1985). Fracture characteristics of three metals subjected to various strains, strain rates, temperatures and pressures. Eng. Fracture Mech. 21 (1), 3148.

35. Kalpakjian, S. (1997), Manufacturing Processes for Engineering Materials, $3^{\text {rd }}$ ed. Addison-Wesley

36. Kleiber, M. and Kollmann, F.G. (1993). A theory of viscoplastic shells including damage. Arch. Mech. 45, 4, 423-437.

37. Korkolis, Y. P., Kyriakides, S. (2008), Inflation and burst of aluminum tubes for hydroforming applications. International Journal of Plasticity; 24, 509-543

38. Korkolis, Y. P., Kyriakides, S. (2009), Path-dependent failure of inflated aluminum tubes International Journal of Plasticity; 25, 2059-2080

39. Korkolis, Y. P., Kyriakides, S., Giagmouris, T., Lee, L.-H., (2010),” Constitutive Modeling and Rupture Predictions of Al-6061-T6 Tubes under Biaxial Loading Paths; J. of App. Mechanics, 2010, Vol. 77 / 064501-1 
40. Kouznetsova, V, Geers, M.G.D., Brekelmans, W.A.M., (2002) Multi-scale constitutive modelling of heterogeneous materials with a gradient-enhanced computational homogenization scheme. Int. J. for Num. Methods in Engineering; 54:1235-1260

41. Kyriakides, S. and Ravi-Chandar, K. (2008) Material Constitutive Relations and Failure Modeling; Future Naval Capabilities Program Review, Washington, DC; 11-18-2008

42. Li Y., Wierzbicki T., (2010), Prediction of plane strain fracture of AHSS sheets with post-initiation softening; Int. J. Solids and Structures, 47, 17; 2316-2327

43. Marciniak, Z., Kuczynski, K., (1967). Limit strains in the processes of stretch-forming sheet metal. Int. J. Mech. Sci. 9 (9), 609-620.

44. McClintock, F.A., (1968). A criterion of ductile fracture by the growth of holes. J. Appl. Mech. 35, 363-371.

45. McClintock, F.A., (1971). Plasticity aspects of fracture. In: Leibowitz, H. (Ed.), Fracture, vol. 3. Academic Press, pp. 47-225.

46. Mechanical Testing and Evaluation, ASM Handbook Vol. 8, ASM International

47. Nahshon, K. and Hutchinson, J. W., (2008), "Modification of the Gurson Model for shear failure", European Journal of Mechanics A/Solids 27, 1-17.

48. Nahshon, K., Pontin, M., Evans, A., Hutchinson, J.W., and Zok, F.W., (2007), "Dynamic Shear Rupture of Steel Plates”, J. Mech. Mat. Stru; Vol. 2, No. 10; pp. 2049-2066

49. Nielsen, K. L. and Tvergaard, V., (2009), "Effect of a Shear Modified Gurson model on Damage Development in a FSW Tensile Specimen”, IJSS, 46; 587-601

50. Nielsen, K.L. and J.W. Hutchinson (2011), "Cohesive Traction-Separation Laws for Tearing of Ductile Metal Plates. Accepted to J. of Impact Engineering

51. Ortiz, M. and Pandolfi, A. (1999), "Finite-Deformation Irreversible Cohesive Elements for Three-Dimensional Crack Propagation Analysis”, IJNME, 44, 1267-1282

52. Perzyna, P. (2005),”The Thermodynamical Theory of Elasto-Viscoplasticity”, Engineering Transactions; 53, 3, 235-316.

53. Perzyna, P. (1984). Constitutive Modeling of Dissipative Solids for Postcritical Behaviour and Fracture. ASME, J. Eng. Materials and Technology, 106, 410-419.

54. Ravi-Chandar, K. (2010) MURI/FNC program review

55. Rice, J.R., Tracey, D.M., (1969). On the ductile enlargement of voids in triaxial stress fields. J. Mech. Phys. Solids 17, 201-217.

56. Rodd, J.L., Phillips, M.P., (1994), Stranding experiments on double hull tanker structures; The advanced double-hull technical symposium. Gaithersburg, MD, USA

57. Rodd, J.L., Sikora, J.P., (1995), Double hull grounding experiments; Fifth international offshore and polar engineering conference. Den Haag, The Netherlands: Int. Soc. Offshore and Polar Engineerns (ISOPE), Golden, CO

58. Simonsen, B.C. and Tornqvist, R., (2004), "Experimental and numerical modeling of ductile crack propagation in large-scale shell structures", Marine Structures; 17; pp. 1-27.

59. Seweryn, A. and Mroz, Z. (1998). On the criterion of damage evolution for variable multiaxial stress states. Int.J. Solids Structures 35, 1589-1616.

60. Shields, M.D., Woelke, P., Abboud, N., Hutchinson, J.W., (2012), Cohesive Zone Modeling of Mode I Ductile Fracture on a Structural Scale; In preparation

61. Song, J. H., Areias, P. M. A., and Belytschko, T., (2006), A Method for Dynamic Crack and Shear Band Propagation with Phantom Nodes; Int. J. Num. Methods Eng., 67; 868893. 
62. Spitzig, W.A., Richmond, O., (1984), The effect of pressure on the flow stress of metals. Acta Metallurgica 32 (3), 457-463.

63. Tvergaard, V., Hutchinson, J. W., (2002), "Two mechanisms of ductile fracture: void by void growth versus multiple void interaction.” Int. J. Solids Structures, 39, 3581-3597.

64. Tvergaard, V., Hutchinson, J.W., (1996), "Effect of Strain-Dependent Cohesive Zone Model on Predictions of Crack Growth Resistance"; Int. J. Solids and Structures, Vol. 33, 20-22; pp. 3297-3308

65. Vaughan, D. K. (2006), FLEX User's Guide - Report UG8298, Weidlinger Associates Inc., Mountain View, CA

66. Voyiadjis, G.Z. and Woelke, P. (2005). General non-linear finite element analysis of thick plates and shells. Int.J. Solids Structures; Vol. 43; Issue 7-8, 1; p. 2209-2242

67. Voyiadjis, G.Z. and Woelke, P. (2006), "Elasto-Plastic and Damage Analysis of Plates and Shells", 2008 Springer-Verlag.

68. Woelke, P., Abboud, N. (2012) "Modeling Fracture in Large Scale Shell Structures”. J. of the Mechanics and Physics of Solids; 60, 12, 2044-2063

69. Woelke, P., Voyiadjis, G.Z. and Perzyna, P. (2006) "Elasto-plastic finite element analysis of shells with damage due to microvoids”. Int. J. Num. Meth. Eng., Vol. 68, (3), pp. 338 -380 .

70. Woelke, P., Chan, K.K., Daddazio, R., Abboud, N. and Voyiadjis, G.Z., (2012), Analysis of shear flexible layered isotropic and composite shells by EPSA; Shock and Vibration, 19; 459-475

71. Woelke, P., Chan, K.K., Daddazio, R., Abboud, N., (2012), Stress-resultant based elastoviscoplastic thick shell model; Shock and Vibration, 19; 477-492

72. Woelke, P., Chan, K.K., Abboud, N., Daddazio, R., Hapij, A., and Voyiadjis, G.Z (2006), Damage Model For Analysis of Isotripic Shells Using EPSA; $77^{\text {th }}$ Shock and Vibration Symposium Proceedings, Monterrey, CA

73. Xu, X.P. and Needleman, A. (1994), Numerical Simulations of Fast Crack Growth in Brittle Solids; J. Mech. Phys. Solids, Vol. 42, No.9; pp.1397-1434

74. Xue, Z., Pontin, M.G., Zok, F.W., Hutchinson, J.W. (2010), Calibration procedures for a computational model of ductile fracture, Engineering Fracture Mechanics, 77; 492-509 